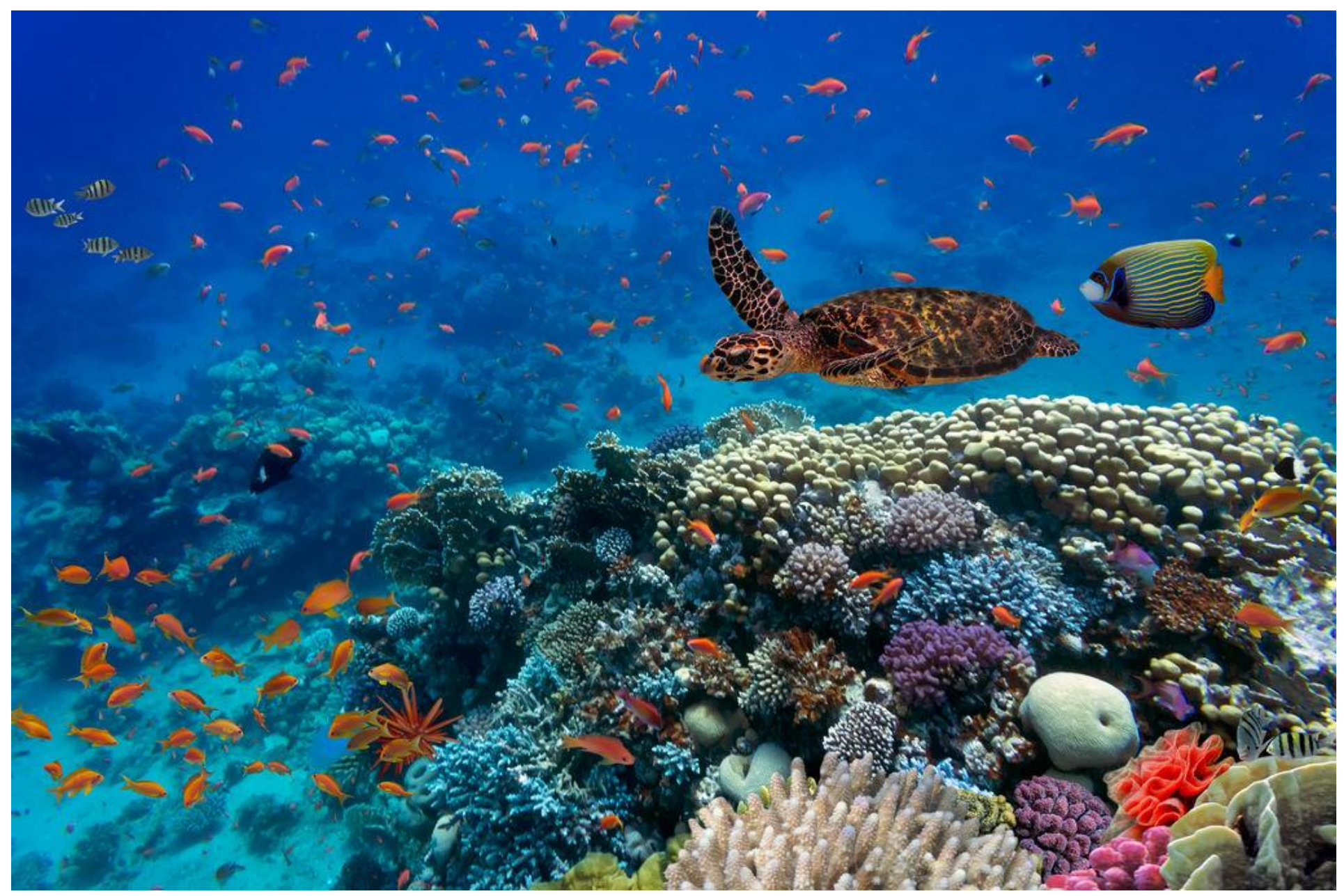

\title{
Framework for a water quality monitoring program for the Caribbean Netherlands
}




\section{Framework for a water quality monitoring program for the Caribbean Netherlands}


Keywords: Water Quality, Monitoring, Coral, Bonaire, St. Eustatius, Saba.

Client: $\quad$ Rijkswaterstaat Water, Verkeer en Leefomgeving

Attn.: Dhr. R Rense

Griffioenlaan 2

3526 LA Utrecht

(Zaaknummer 311163489)

Wageningen Marine Research is ISO 9001:2015 certified.

This report can be downloaded for free from https://doi.org/10.18174/554541

Wageningen Marine Research provides no printed copies of reports

(C) Wageningen Marine Research

Wageningen Marine Research, an institute Wageningen Marine Research accepts no liability for consequential damage, nor within the legal entity Stichting for damage resulting from applications of the results of work or other data Wageningen Research (a foundation under obtained from Wageningen Marine Research. Client indemnifies Wageningen Dutch private law) represented by Marine Research from claims of third parties in connection with this application. Drs.ir. M.T. van Manen, Director Operations All rights reserved. No part of this publication may be reproduced and / or published, photocopied or used in any other way without the written permission of the publisher or author.

KvK nr. 09098104,

WMR BTW nr. NL 8113.83.696.B16.

Code BIC/SWIFT address: RABONL2U

IBAN code: NL 73 RABO 0373599285

A_4_3_2 V31 (2021)

2 of 52 | Wageningen Marine Research C074/21 


\section{Contents}

Contents

Summary

1 Introduction

1.1 About this framework

$2 \quad$ Policy goals and measures

3 Establishment of objectives

$\begin{array}{lll}3.1 & \text { Spatial boundaries and scope } & 10\end{array}$

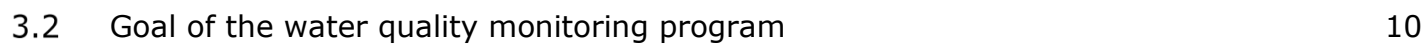

$\begin{array}{lll}3.2 .1 & \text { Types of water quality monitoring } & 11\end{array}$

$4 \quad$ Previous studies on coastal surface water $\quad 12$

$\begin{array}{llr}5 & \text { Selecting water quality indicators } & 14\end{array}$

$\begin{array}{lll}5.1 & \text { Criteria for indicators } & 14\end{array}$

$\begin{array}{lll}5.2 & \text { Relevant indicators } & 14\end{array}$

$\begin{array}{ll}5.3 & \text { Selection of water quality indicators } \\ \end{array}$

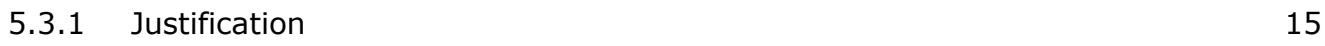

5.3.2 Validation and analytical costs 17

$\begin{array}{ll}5.4 & \text { Application of threshold values } \\ \end{array}$

$\begin{array}{ll}\text { 5.4.1 Threshold values and limits of quantification } & 20\end{array}$

$6 \quad$ Information gathering strategy $r 22$

$\begin{array}{llr}6.1 & \text { Considerations about sampling frequency } & 22\end{array}$

\begin{tabular}{ll}
6.2 & Considerations about sampling locations \\
\hline
\end{tabular}

$\begin{array}{lll}6.2 .1 & \text { Surface water } & 23\end{array}$

6.2.2 Groundwater $\quad 24$

$\begin{array}{lll}6.2 .3 & \text { Run-off water } & 24\end{array}$

$\begin{array}{ll}6.3 & \text { Semi-continuous and time integrated measurements }\end{array}$

$\begin{array}{lll}\text { 6.3.1 Semi-continuous measurements } & 25\end{array}$

6.3.2 Time-integrated measurements and bioindicators $\quad 25$

$\begin{array}{lll}6.4 & \text { Sampling strategies } & 26\end{array}$

6.4.1 Sampling strategy for monitoring surface (coastal) water quality 26

6.4.2 Pragmatic strategy for monitoring effectiveness of measures 30

$\begin{array}{lll}6.4 .3 & \text { Analytical costs } & 31\end{array}$

6.4.4 Capacity needs $\quad 33$

$7 \quad$ Capacity and Regional cooperation $\quad 35$

$\begin{array}{lll}7.1 & \text { Technical requirements } & 35\end{array}$

$\begin{array}{lll}7.2 & \text { Cooperation } & 36\end{array}$

$8 \quad$ Recommendations $\quad 37$

$\begin{array}{lll}\text { 8.1 Information gathering strategy and criteria for evaluation } & 37\end{array}$ 
Justification

Annex 1: Overview of relevant case studies

Annex 2: Relevant policy frameworks and treaties

Annex 3: List of regional marine laboratories

51 


\section{Summary}

The NEPP (Nature and Environment Policy Plan, 2020-2030) creates an integral framework for the management of the natural environment in the Caribbean Netherlands. Special attention is given to the protection and restoration of the coral reefs and to increase the resilience of these ecosystems against the impacts of climate change. The current environmental conditions for coral reefs are considered sub-optimal, and therefore the NEPP strategic goal nr.1 is: Reversing the trend of coral reef degradation to create healthy, resilient and restored coral reefs, ensuring well-being in the Caribbean Netherlands.

To reach this goal investments will be made in the coming years to reduce the impact of local pressures with respect to erosion, run-off and discharge of untreated wastewater. In addition, a water quality monitoring program (WQ-monitoring program) will be developed to establish the actual water quality status in the coastal zone of the different islands and to be able to detect the effectiveness of measures to improve it. Rijkswaterstaat requested Wageningen Marine Research to develop a first framework for this WQ-monitoring program.

This framework aims to:

- Specify the objectives of a WQ-monitoring program in the light of the actual policy goals;

- Identify relevant indicators of water quality that can be included in the monitoring program;

- Propose options for a WQ-monitoring program with respect to frequency and spatial coverage;

- Create an inventory of already present monitoring networks and analytical facilities and give a rough indication of the budgets involved.

A first set-up of the framework was discussed in two online sessions in October/November 2020 with stakeholders, facilitated by Wageningen Marine Research.

The framework presented in this report can guide in the designing of a basic governmental WQmonitoring program and more dedicated research and development programs to answer specific questions on the islands.

Two sampling strategies are described to monitor the surface coastal water quality, one comprehensive and one less intensive. The advantage of monitoring the coastal water is that the monitoring results can directly be related to the conditions at the coral reefs. However, due to water currents and dilution an intense (both spatial as in frequency) sampling program is required. But even then it may be difficult to link the monitoring results with specific pressures and to determine the effectiveness of policy measures. For this aim monitoring groundwater and run-off water quality is probably more efficient. The best option for a monitoring program therefore is to combine a yearly monitoring of ground water and run-off water and biological monitoring of for instance coverage of cyanobacterial mats, with a more or less intensive monitoring of the coastal water at a lower frequency, for instance every 3 years.

The design of the actual monitoring program should be tailored for each island. 


\section{Introduction}

The NEPP (Nature and Environment Policy Plan, 2020-2030) creates an integrative framework for managing the natural environment in the Caribbean Netherlands. With the support of the Dutch government, the public entities of each of the three islands will develop their implementation plans that will serve as action plans for the local environmental policy.

The unhealthy status of valuable ecosystems in the Caribbean Netherlands, and the need for effective management of the responsible pressures form the basis of the goals formulated in the NEPP. Special attention is given to protecting and restoring the coral reefs and increasing their resilience to the impact of climate change.

Meesters et al., (2019) describe the main threats to coral reef ecosystems in the Caribbean Netherlands. Population growth and increased economic activity (mainly tourism) have led to increased wastewater and solid waste. In addition, coastal development, brine water discharge and free-roaming livestock are responsible for severe damage to land and vegetation, resulting in erosion with run-off during rain events, storm and wind reversals. These processes increased the overall pollution of coastal water in the form of increased nutrient and sediment levels and pathogens, resulting in reefs that are increasingly dominated by macro-algae and cyanobacteria (De Bakker et al., 2017; Van der Geest et al., 2020).

Improving this situation is established in the NEPP as strategic goal 1: Reversing the trend of coral reef degradation to create healthy, resilient and restored coral reefs, ensuring well-being in the Caribbean Netherlands.

The following practical policy goals have been formulated to achieve this strategic goal in the NEPP:

1.1 Control erosion and run-off

1.2 Effective waste and wastewater management

1.3 Coral reef restoration

To reach these goals, measures to reduce the impact of local pressures concerning erosion, run-off and discharge of untreated wastewater and brine will be defined and laid down in implementation agendas for each of the three islands. These agendas will include implementing an effective water quality monitoring program for ground- and seawater by 2024. In preparation for this, Rijkswaterstaat requested Wageningen Marine Research to develop the first framework, which should guide the design of island-specific water quality (WQ) monitoring programs for coastal water in 2021. Ideally, this coastal water quality monitoring program will be combined with an overall environmental monitoring program, which should also include monitoring of ground water, run-off water and other matrices that are relevant in order to get a good insight into the effectiveness of the measures that will be taken to improve the water quality.

\subsection{About this framework}

This report describes a framework for monitoring the water quality in the coastal zone of the three Caribbean Netherlands islands. This water quality monitoring should become part of a total monitoring program that ideally also includes monitoring of ground water, run-off water, wastewater, brine water, effluents from wastewater treatment plants, and ecological monitoring of the status of the coral reef. The framework contained in this document aims to:

- specify the objectives of a WQ-monitoring program in the light of the actual policy goals;

- identify relevant indicators of water quality that can be included in the monitoring program;

- propose options for a WQ-monitoring program for frequency and spatial coverage;

- give a rough indication of the needs for (technical) capacity and budgets involved.

During the preparation of this framework, two online sessions with stakeholders were organised to discuss and decide about specific topics. The following organisations were represented during these 
meetings: Directorate-General for Public Works and Water Management (Rijkswaterstaat), Openbaar Lichaam Bonaire (OLB), STINAPA, STENAPA, CNSI, Saba Conservation Organisation. Wageningen Marine Research facilitated the meetings.

Within the time available for this assignment, it was not possible to be complete in all aspects. Some parts are based on expert judgement, and where the authors feel that additional information is required, this is emphasised. Due to poor information availability, the objective to 'provide an inventory of already present monitoring networks and analytical facilities' could not be met.

During the evaluation of the final draft version of this framework with OLB, it was decided to add more information about monitoring groundwater and run-off water. 


\section{Policy goals and measures}

The general policy goals for the Caribbean Netherlands are presented in the NEPP. The NEPP also relates to local, regional or global policies or treaties that the Netherlands and/or the Dutch Caribbean have committed to and which water quality aspects are essential (see Annex 2). For water quality, the following short and long term goals can be extracted from the NEPP:

- In the short term, it is the goal that the water quality improves to a level determined by water quality measurements that do not hamper the recovery and further development of coral reefs.

- $\quad$ In the long term, nature, thus including the coral reefs of the Caribbean Netherlands, will reach good status by 2050 .

In order to improve the coastal water quality, the NEPP contains the following measures per island:

Bonaire: Erosion prevention (remove roaming cattle, sustainable coastal development policies), brine water management and effective treatment of wastewater.

Saba: $\quad$ Erosion prevention (remove roaming cattle), effective treatment of wastewater and solid waste.

Sint Eustatius: Erosion prevention (remove roaming cattle and replanting trees) and effective treatment of wastewater.

The measures to reach these goals will be included in the implementation agendas currently being drafted for each of the three islands. Listed below are the goals related to water quality that are included in the draft implementation agenda, with their targets. The numbered coding is copied from the draft implementation agenda and relates to the numbering of the policy goals formulated in the NEPP. Targets 1.2.1.b. and 1.2.1.c. directly relate to the WQ-monitoring program.

\section{Goal 1.1: Control erosion and run/off}

1.1.1 Fencing cattle to reduce erosion (to be included in the implementation agenda)

1.1.2 Rainwater management: Reducing surface water run-off by $50 \%$ in 2030

1.1.3 Sustainable Coastal development: No sand enhancement if erosion cannot be prevented

Goal 1.2: Waste and wastewater management to improve water quality

1.2.1: Adequate wastewater treatment on Bonaire:

1.2.1.b. Implementing standards for coastal seawater quality by 2024

1.2.1.c. Implement an effective water quality monitoring program for ground- and seawater by 2024

1.2.1.a. Effective wastewater treatment by 2030

1.2.1.e. Complete ban and enforcement of cesspits and leaking septic tanks on all three islands by 2030

1.2.1.f. Zero waste discharge of any vessel in the territorial waters by 2024

1.2.1.d. Ban on irrigation with treated wastewater within an adequate distance from the high-water mark by 2024

1.2.1.g. Establish and enforce standards for the environmental impact of industries by 2030

1.2.1.h. Reduced run-off from agrochemicals by 2030

- Prevention of brine water discharge into the marine park

1.2.2: $\quad$ Solid waste management

1.2.2 c. Control seepage of pollutants from current landfills into the ground and surface water by 2030

1.2.2 g. Monitoring of marine litter and stimulate cleaning up the sea and coastal areas where plastics accumulate by 2024 
Figure 1 a schematic presentation is given of how these aspects are related to the local water quality. This figure also includes some examples of possible response measures that may reduce the pressure on the water quality.

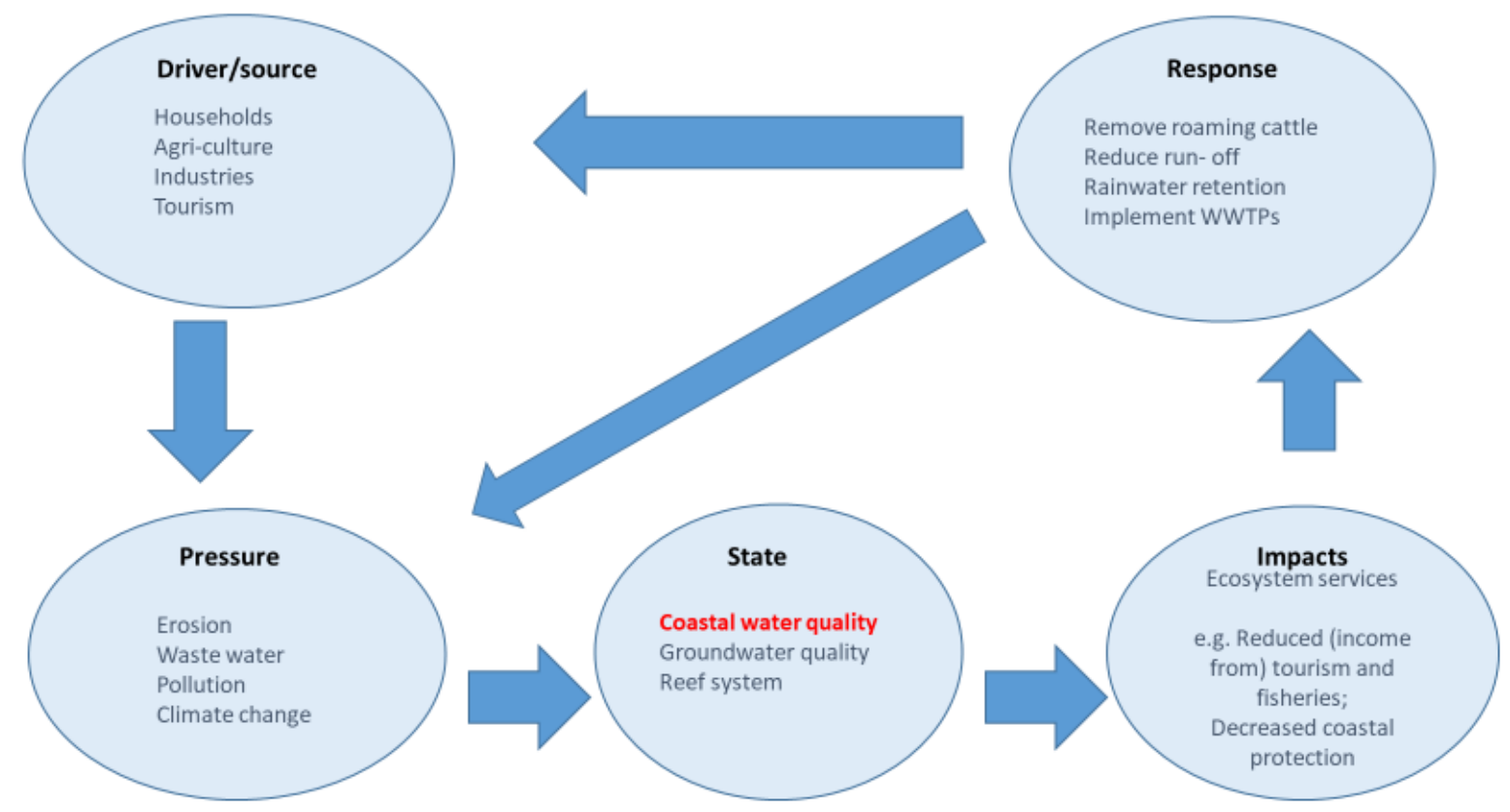

Figure 1 Driver-Pressure-State-Impact-Responses (DPSIR) scheme of local aspects related to the coastal water quality of the Caribbean Netherlands. WWTP = Waste water treatment plant 


\section{Establishment of objectives}

\subsection{Spatial boundaries and scope}

At first, the WQ-monitoring program covered by this document was restricted to coastal (surface) water and did not include ground water, run-off water or other matrices. However, after stakeholder discussions, a paragraph on considerations about groundwater monitoring is included in section 6.2.2 since this can be of substantial value in interpreting the results of the WQ-monitoring program in the coastal zone. In addition, monitoring groundwater and run-off water are included as sampling strategies (section 6.4).

The WQ-monitoring program includes only water quality parameters considered critical for the condition of the coral reefs since the focus of the NEPP strategic goal one is 'Reversing the trend of coral reef degradation...'. Finally, since the focus is on coastal coral reefs in the Caribbean Netherlands, located mainly in the marine park zones (Figure 2), we consider these the target areas where the WQ-monitoring program should at least apply.
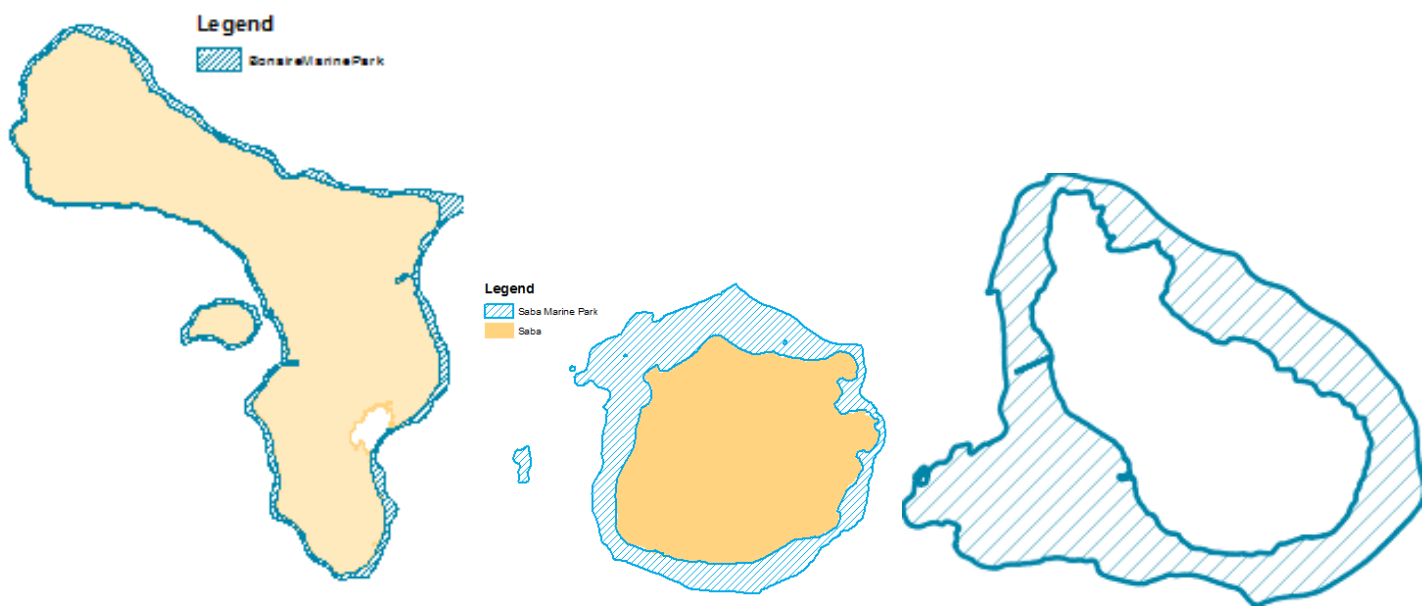

Figure 2 Marine park zones (hatched blue) of (from left to right) Bonaire, Saba and St. Eustatius.

\subsection{The goal of the water quality monitoring program}

The immediate goal of the WQ-monitoring program is to determine the actual status of the water parameters that are critical for coral health in the coastal waters of the Caribbean Netherlands islands. The collected data should allow assessment of the effectiveness of policy measures to improve coral health in the coastal waters of the Caribbean Netherlands islands by improving water quality (see paragraph 2) and allow the identification of areas of concern or progress. In this way, the results form an important input for an adaptive management cycle.

The WQ-monitoring program must establish the actual coastal water quality status for the parameters critical to coral reef health. It must give sufficient insight into local and temporal variation to determine where water quality criteria are already met and where extra measures are required to reach these. In the latter case, the monitoring data could indicate which are the most likely pressures. In the longer term, the collected data must give insight into trends in time to assess the effectiveness of taken measures and safeguard the coastal waters. The final goal is that eventually, water quality is no longer a limiting factor in the recovery and development of a healthy and resilient coral reef. 


\subsubsection{Types of water quality monitoring}

Based on various information needs, we distinguish the following monitoring strategies:

Status monitoring: A monitoring program that runs over a more extended period (years) describes (trends in) critical water quality indicators.

Pressure/effect monitoring: Monitoring aimed at describing the intensity and extent of a specific pressure (e.g. run-off after a rain event, wastewater or brine water discharges) on the water quality in a specific area, situation and/or time-frame, with the option to assess the effectivity of measures taken to reduce the pressure.

Incident monitoring: Monitoring that takes place after an incident (e.g. storm event, accident, oil spill etc.) to assess its immediate impact on water quality and potentially its recovery.

In this report, we describe requirements of long-term status monitoring that generally apply to all three Caribbean Netherlands islands. Pressure and incident monitoring of water quality always relate to specific situations in specific locations. Such tailored and often short term monitoring programs are therefore best designed in the island-specific monitoring programs planned for 2021 . The expertise, insights, and analytical capacity that need to be developed in the proposed status monitoring program will be directly applicable to the design of additional pressure and incident monitoring of water quality in the future.

The information from this basic governmental WQ-monitoring program should:

- In the short term, provide insight into the status of water quality in the coastal zone;

- In the medium term, guide tailoring the monitoring program to give the best information possible;

- In the longer term, provide insight into local and temporal differences and trends in water quality;

- $\quad$ Provide data to assess the effectiveness of policy measures on water quality;

- Provide data to assess relationships between (change in) water quality and results from ecological (reef) monitoring

- It could be used as a basic governmental WQ-monitoring program for more dedicated research and development programs on the islands to answer specific questions 


\section{Previous studies on coastal surface water}

Exploratory analysis of existing data and studies might yield information that can help locate hot spots or critical areas, identify important covariates, or account for such characteristics as seasonality in the design of the monitoring program (USEPA, 2005). In this section, we review lessons learned in available reports and papers on water quality in the coastal surface water of the BES islands. The quick search resulted in a limited number of reports and papers that were all about Bonaire. No results for Saba and Sint Eustatius were found nor received on time to include in this report. A comprehensive overview of the studies and their summaries is reported in Annex 1: Overview of relevant case studies.

Studies considering groundwater sampling and quality (at Bonaire) are described in paragraph 6.2.2.

Studies reviewed:

\begin{tabular}{|l|l|l|l|}
\hline Source & What & Years & Island \\
\hline LaPointe and Mallin (2011) & $\begin{array}{l}\text { Paper, reports and data, raw data of } \\
\text { seasonal sampling for nutrients } \\
\text { (ammonium, nitrate, DIN, SRP, TDN, } \\
\text { TDP), (Chl a), stable nitrogen isotopes } \\
\left(\delta^{15} \mathrm{~N}\right) \text { in reef macro-algae, and biotic } \\
\text { Cover of shallow and deep reef sites }\end{array}$ & $\begin{array}{l}2006- \\
2008\end{array}$ & Bonaire \\
\hline Slijkerman et al. (2014) & $\begin{array}{l}\text { Paper, data, reports on seasonal sampling } \\
\text { Raw data of seasonal sampling for } \\
\text { nutrients (ammonium, nitrate, DIN, SRP, } \\
\text { TDN, TDP), (Chl a), stable nitrogen } \\
\left.\text { isotopes ( } \delta^{15} \mathrm{~N}\right) \text { in reef macroalgae, of } \\
\text { shallow and deep reef sites }\end{array}$ & 2013 & Bonaire \\
\hline Physis 1-21 student & Various & Bonaire \\
\hline reports & Deep reef research on nutrients and algae & & Bonaire \\
\hline Pelagia report & $\begin{array}{l}\text { Nutrients, bacteria, epiphytes, hard } \\
\text { substrates }\end{array}$ & Bonaire- Lac \\
\hline Slijkerman et al. (2010) & & \\
\hline
\end{tabular}

The nature of the studies was to explore water quality at various sites, mainly on the west coast of Bonaire. Except for Lac, no studies exist for the east coast. Studies covered the periods 2006-2008, 2010, and 2011-2013. Additional student reports from 2006-2018 reflect anecdotal results, but these are not included in this review due to time limitations. Sampling was performed at various depths, and variability differed based on the water quality indicator reported. Shallow reefs showed higher water quality variability than deeper reefs, whereas water quality also varied greatly in space between sampling locations. A wide range of indicators was applied (nutrients, urea, stable isotopes, bacteria). Both sampling and analytical methodologies differ between studies (e.g. number of replicates, handling and storage, laboratories contracted). The studies report limited variability on indicators that reflect nutrient levels and chlorophyll-a. Stable isotopes $\left(\delta^{15} \mathrm{~N}\right)$ were occasionally included as indicators of nutrient sources and showed high variability within a sampling location per sampling moment.

Below an extraction of the lessons learned is presented (both drafted in the papers and reports and based on our interpretation):

- Indicators reflecting apparent spatial and temporal differences are $\mathrm{DIN}, \mathrm{PO}_{4}$, chlorophyll-a. Bacteria numbers reflect variable pressures in time and space, indicating risk for diseases, and are thus relevant.

$\delta^{15} \mathrm{~N}$ stable isotope ratios in algae reflect longer-term nutrient conditions, are cost-effective, but did not show spatial and temporal differences on Bonaire (but did on Curacao) (Slijkerman et al., 2014; Lapointe and Mallin, 2011). Nevertheless, the inclusion of this indicator is 
interesting, as it could be used to assess the effect of the installation of the sewage treatment plant on Bonaire. The use of stable isotope analysis as a time-integrated indicator for nutrient enrichment should be evaluated. It is advised to include the indicator within the first baseline monitoring on all three islands but to discard it in the structural program if the values are too variable to assess differences in time and space.

- $\quad$ Dissolved inorganic nutrient levels (DIN, PO4) indicate eutrophic conditions at some moments and some locations by exceeding the threshold values (Slijkerman et al., 2014; Lapointe and Mallin, 2011). The question remains whether levels of inorganic nutrients below the threshold indeed reflect a healthy ecosystem. Elevated inorganic nutrient concentrations can indicate influx from, for instance, sanitary waste water, but low concentrations do not necessarily reflect a pristine situation. Nutrients are in constant flux, and available inorganic nutrients are usually rapidly used for primary production and transformed into 'organic nutrients'. Therefore, the relevance and significance of low levels of inorganic nutrients should be evaluated in context with the ecological status of the reef.

- Multiple seasons and years should be sampled to assess background variability of the measured variables over time and to assess seasonal trends. For example, the four-times water sampling over two years by Slijkerman et al. (2014) showed some trends in nutrient levels, but not all indicators showed strong enough responses to be statistically significant. A more prolonged monitoring or higher frequency duration could help unravel the true nature of the detected trends.

- Water quality values (e.g. nutrient concentrations) varied greatly in space, suggesting the importance of local effects, which should be taken into account in the design of a monitoring program. The east coast of Bonaire was not included in water quality monitoring studies but is important because the area may provide good reference locations for good water quality. Future human activities may also present pressures on water quality in this area.

- $\quad$ Replicate sampling in time and space, meaning in different seasons, after torrential rains, at different locations and various depths, is needed to understand the observed variability in water quality parameters. Only when the different sources of variation are known data of a monitoring program can efficiently be interpreted. Shallow reefs showed higher variability than deeper reefs, indicating a larger heterogeneity and influences.

- This WQ-monitoring program should be integrated and performed simultaneously with biological monitoring and with pressure monitoring (e.g. ground water quality, degree of sediment and nutrient run-off) 


\section{$5 \quad$ Selecting water quality indicators}

\section{Indicator or parameter?}

In this document we use the word indicator for all descriptive measures. We understand that strictly speaking these are parameters, and only become indicators after interpretation on the basis of for

instance threshold levels.

\subsection{Criteria for indicators}

For each island, a WQ-monitoring program has to be developed. Besides general indicators for water conditions critical for reef development, it should also contain a set of indicators that can be linked to local sources and stressors and the consequences for the coral reef. Criteria for effective water quality indicators are listed in Table 1. Preferably an effective indicator can be linked to pressure relevant for coral health and/or to a driver of interest. It allows reliable, accurate and cost-effective measurements and can be assessed against a threshold value for a healthy situation.

Table 1 Selection criteria for indicators to assess changes in water quality and the effect on corals and coral communities (Based on Cooper et al.2009, modified based on expert knowledge and applicability to the Caribbean Netherlands). Not all criteria can be met in practice, and the ideal indicator should meet as many criteria as possible.

\begin{tabular}{|l|l|}
\hline Criterium & Definition \\
\hline Specificity & $\begin{array}{l}\text { The indicator can be linked to a pressure of interest. } \\
\text { The magnitude of the indicator's response should reflect the intensity and duration of the } \\
\text { stressor of interest (chronic vs acute/pulse stress, and effectivity of measure(s) taken to } \\
\text { reduce the impact of a specific pressure). }\end{array}$ \\
\hline Variability & $\begin{array}{l}\text { Responses of indicators should be consistent over the full range of spatial and temporal } \\
\text { scales. Ideally, there should be low background variability, although a change in variance } \\
\text { can itself be used as an indicator of impact or change in specific aspects of water quality. }\end{array}$ \\
\hline Practicality & $\begin{array}{l}\text { Measurements of indicators should be cost-effective, easy to measure, non-destructive } \\
\text { and independent of the observer. }\end{array}$ \\
\hline Relevance & Indicators should be ecologically relevant or directly linked to a pressure of interest. \\
\hline Evaluation & $\begin{array}{l}\text { Indicators and corresponding values or concentrations should ideally be assessed against } \\
\text { threshold values or reference values indicating a desired environmental status. }\end{array}$ \\
\hline
\end{tabular}

\subsection{Relevant indicators}

The health and resilience of coral reefs are steered by a complex combination of environmental and biological conditions. Apart from natural factors (e.g. predation, grazing, competition, disease, storms), stressors include adverse environmental conditions resulting from human activities (e.g. fisheries, coastal development, sewage, chemical contamination, climate change). Some of these factors act over regional and/or global scales that cannot be managed locally (e.g. global warming, ocean acidification). Yet, other factors act at a more local scale, which allows them to be managed to increase the resilience of the reefs to global and regional pressures. An overview of the main factors affecting the coral reefs of the Caribbean Netherlands, as given by Meesters et al. (2019), is shown in Figure 3. It indicates that coastal waters' elevated sediment concentrations (mainly from erosion/runoff), nutrients, organic matter, and pathogens (mainly from sewage leakage) form the major threats to a healthy coral reef. In addition to the primary factors indicated by Meesters et al. (2019), discharge of brine water from drinking water production can reduce water quality, as well as chemical contamination, for instance, at locations where heavy metals or oil compounds leak from land-fills or 
industry into the groundwater, or where components from UV-sunscreens (Wijgerde et al., 2020) that tourist uses exceed safe levels in coastal waters.

The set of indicators included in the WQ-monitoring program should give insight into all potential threats to coral reefs relevant to the local situation.

\section{Positive effect/increase}

Negative effect/decrease

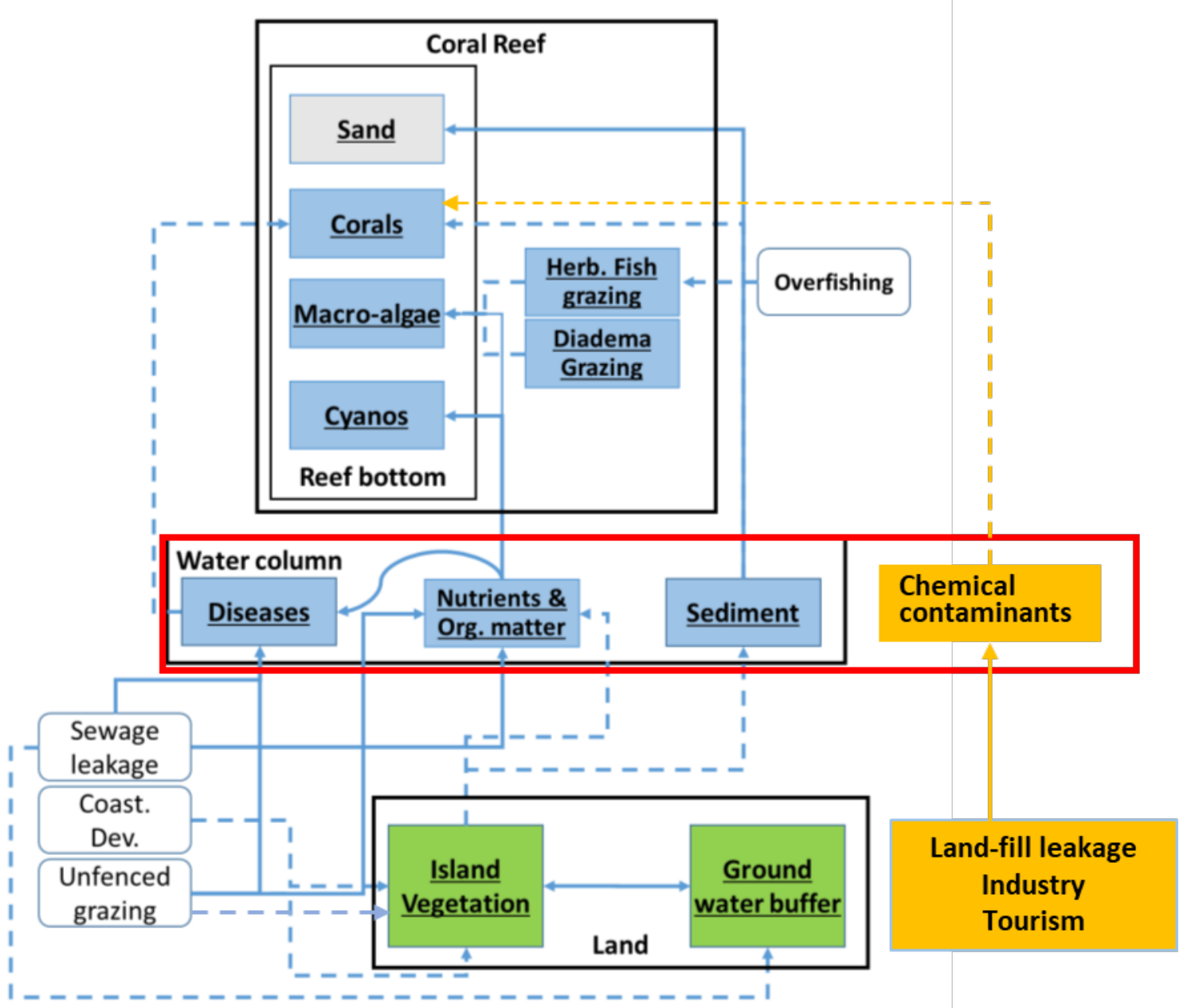

Figure 3 Schematic overview of the components of a coral reef and the local factors with the strongest impact on the condition of the corals that are competing for space with macro-algae and cyanobacterial mats. Dotted lines indicate a negative/inhibiting effect, full lines indicate a positive/stimulating effect. The basic figure showing the main factors is adapted from Meesters et al.(2019). For completeness with respect to the scope of the WQ-monitoring program the orange boxes and lines were added. The red box 'water column' shows the pressures that are subject of the water quality monitoring program to be developed.

\subsection{Selection of water quality indicators}

\subsubsection{Justification}

Table 2 provides an overview of water quality indicators used in the WQ-monitoring program and their relation to the pressures mentioned in Figure 3. Each of the indicator groups is briefly described below. 
Table 2 Rationale behind water quality indicators relevant for the Water Quality monitoring program. Modified from Becking and Slijkerman (2012).

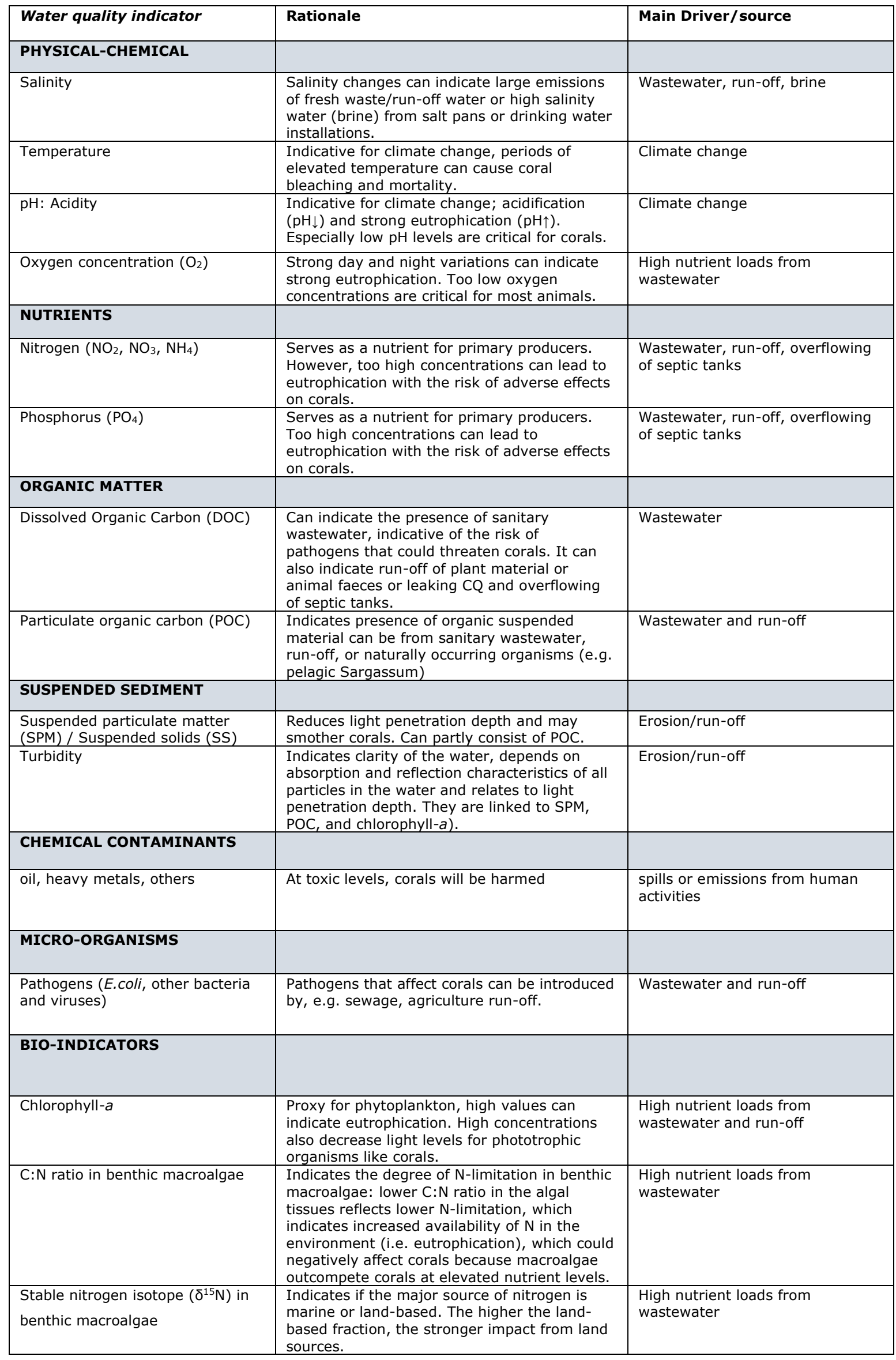

The physical-chemical indicators like salinity, temperature, $\mathrm{pH}$ and oxygen concentration are not the most powerful indicators for the major local pressures. They are, however easy to measure on-site 
and provide a general picture of the water characteristics. They are also often bundled in one instrument that can measure at high frequency when lowered from the surface to the bottom, giving an accurate picture of water characteristics through the whole water column. They should, therefore, always be included in a WQ-monitoring program. For scientific research related to ocean acidification, sophisticated methods are necessary to detect minimal changes in $\mathrm{pH}$ in seawater. In the scope of this monitoring program, a typically calibrated $\mathrm{pH}$ electrode that measures $\mathrm{pH}$ with one decimal is regarded as sufficient.

The main nutrients needed for primary production are nitrogen and phosphate. After being released in an inorganic form due to excretion (faeces, urine) from organisms, from decaying dead organic material, or via sanitary wastewater or run-off, they are assimilated during primary production into organic forms (proteins etc.) that are being used higher up in the food chain. Both the inorganic and the organic form of nutrients can be measured. The inorganic forms $\left(\mathrm{NO}_{2}, \mathrm{NO}_{3}, \mathrm{NH}_{4}\right.$, ortho- $\left.\mathrm{PO}_{4}\right)$ indicate the readily available nutrients for primary producers. In a healthy ecosystem, these nutrients will be rapidly used, keeping background concentrations low. High levels of dissolved inorganic nutrients can thus indicate a recent influx, while the concentration of organic nutrients, mainly included in (micro)organisms in the water column, gives a better insight into the availability in the longer term.

Organic matter in a water sample, often expressed as organic carbon, can be present in particulate form, mainly consisting of micro-organisms and suspended organic matter, and in dissolved form (e.g. humic acids). Both forms can be expected in high concentrations in untreated sanitary wastewater. In treated wastewater, less suspended material will be present, but concentrations of dissolved organic matter will still be high. In run-off water (that can contain a lot of organic matter from animal faeces) and groundwater, the concentrations of organic matter can vary related to the land/sediment type. Sediments can reach the coastal water during a run-off event. Depending on the size of the sediment particle, it will rapidly sink and settle (sand fraction) or stay suspended for a longer period (clay fraction), which allows it to spread over a larger area. The dispersal of sediment particles also depends on local hydrodynamics (e.g. wave and current conditions). Suspended sediment reduces light penetration depth while settling sediment can smother corals. Apart from sand and clay particles that form the mineral fraction, total suspended matter in the water column also consists of an organic fraction formed by organic material. This organic fraction correlates with the particulate organic carbon described above.

Chemical contaminants can harm corals if present in concentrations that exceed the so-called No Effect Concentration specific for the substance and the species of interest. The presence of oil compounds, heavy metals and UV-blockers might form a potential risk for coral reefs, most likely only on a local scale in the direct vicinity of sources like industry, leaking land-fills or high tourist densities.

Micro-organisms and viruses have harmed coral reefs in the past, and in some cases, coral diseases seem related to the presence of human intestinal bacteria in the water (Meesters et al., 2019). It is not clear if these bacteria directly cause the observed disease or if the presence of these bacteria reflects the presence of sanitary wastewater that negatively affects the conditions for the coral. In both causes monitoring human intestinal bacteria concentrations in seawater is helpful to understand the pressure on the coral reefs. In addition, DNA sampling may allow the detection of the presence of harmful bacteria and viruses. However, in situ environmental DNA (eDNA) measurement is still under development and not all relevant DNA sequences are known. Bio-indicators are responses in or by (parts of) living organisms that can be used to assess the health of an ecosystem (Parmar et al., 2016). Any resulting changes observed in bio-indicators are thus a (net) result of ecologically relevant changes in environmental conditions such as water quality plus ecological feedback loops (Fabricius et al., 2012). The bio-indicators mentioned in Table $\mathbf{2}$ are all indicators for eutrophication. Relevant bioindicators for erosion-related sedimentation are not (yet) identified.

\subsubsection{Validation and analytical costs}

A rough estimate of the analytical costs per sample for each indicator is presented in Table 3.

Relatively cheap physical-chemical analyses that electrodes can perform should always be included in any WQ-monitoring program since they give a general impression of water characteristics. On the 
other hand, analyses of chemical contaminants are relatively expensive, but as these substances are only expected to cause problems in specific situations/locations, these analyses can be restricted to specific sampling positions/moments that are considered relevant.

Table 3 further contains indicator-specific scores for the criteria that determine effective indicators, as presented in Table 1. The majority of the indicators are sufficiently specific (S) for either the stressor or a critical water condition. Exceptions are dissolved oxygen concentration, a generic indicator, and particular organic carbon, that could be affected by organic matter from wastewater and the natural presence of plankton, micro-organisms and macroalgae in the water column. Too little knowledge about the local temporal and spatial variation of most indicators is available to conclude about the criteria of variability (V). This information should be collected during the first monitoring period and used in an evaluation. Most indicators score well on practicality $(P)$, indicating that good results can be achieved with routine lab procedures. Identification of suspended matter's mineral fraction might cause problems due to the expectation that these values will generally be very low, which requires highly accurate analyses. Analyses of $\mathrm{C}: \mathrm{N}$ ratios and nitrogen stable isotope signatures are not a problem but require specialised, sophisticated analytical equipment. All indicators listed are considered relevant for the BES Islands, although a question mark could be placed at particular organic carbon for the reasons that also apply to this indicator's specificity. Finally, the table shows which indicators threshold levels are available either from the NEPP or from published literature (Table 4). The following paragraph discusses how these threshold levels can be applied and how they determine the selection of an analytical method. 
Table 3 List of indicator-specific costs per sample, methodological aspects, and scores for the criteria as listed in Table 1: Specificity (S), Variability (V), Practicality $(p)$, Relevance $(R)$ and Evaluation (E). Scores are presented as ' $Y$ ' $=$ Yes; ' $N$ '=No; '?'= potentially $Y e s$, but more data is needed. $A$ bold ' $Y$ ' in the Evaluation column indicates that a threshold level is included in the NEPP, while ' $y$ ' indicates that threshold levels for coral reefs are available from literature but not included in the NEPP; for threshold levels, see Table 4.

Indication of costs reflects the costs currently charged by Dutch laboratories. Purchasing equipment is not included in this table. Costs depend on bulk analyses and could deviate depending on the contract.

\begin{tabular}{|c|c|c|c|c|c|c|c|c|}
\hline PHYSICAL-CHEMICAL & $\begin{array}{c}\text { C per } \\
\text { sample }\end{array}$ & $\begin{array}{c}\text { Sample } \\
\text { treatment/storage }\end{array}$ & Analysis & $\mathbf{S}$ & $\mathbf{V}$ & $\mathbf{P}$ & $\mathbf{R}$ & $\mathbf{E}$ \\
\hline Temperature & 5 & at location & electrode & Y & Y & Y & Y & $\mathrm{N}$ \\
\hline $\mathrm{pH}$ & 5 & at location & electrode & Y & $\mathrm{Y}$ & Y & $\mathrm{Y}$ & $\mathrm{N}$ \\
\hline Salinity & 5 & at location & electrode & $\mathrm{Y}$ & $\mathrm{Y}$ & Y & $Y$ & $\mathrm{~N}$ \\
\hline Dissolved oxygen & 5 & at location & electrode & $\mathrm{N}$ & $\mathrm{Y}$ & Y & $\mathrm{Y}$ & $y$ \\
\hline Light penetration depth & 5 & at location & electrode & $\mathrm{Y}$ & $?$ & Y & $\mathrm{Y}$ & $\mathrm{N}$ \\
\hline \multicolumn{9}{|l|}{ NITROGEN } \\
\hline Ammonium & 25 & filtrated frozen & Spectrophotometric & $\mathrm{Y}$ & $?$ & Y & $\mathrm{Y}$ & $\mathrm{N}$ \\
\hline Nitrite & 25 & filtrated frozen & Spectrophotometric & Y & $?$ & Y & $\mathrm{Y}$ & $\mathrm{N}$ \\
\hline Nitrate & 25 & filtrated frozen & $\begin{array}{l}\text { Spectrophotometric } \\
=[\mathrm{NH} 4]+[\mathrm{NO} 3]+[\mathrm{N}\end{array}$ & Y & $?$ & Y & Y & $\mathrm{N}$ \\
\hline Dissolved Inorganic Nitrogen & - & By calculation & O2] & $\mathrm{Y}$ & $?$ & Y & $\mathrm{Y}$ & $\mathbf{Y}$ \\
\hline Particulate organic nitrogen & 25 & & & Y & $?$ & Y & $\mathrm{Y}$ & $\mathbf{Y}$ \\
\hline \multicolumn{9}{|l|}{ PHOSPHOROUS } \\
\hline Ortho-phosphate & 25 & filtrated frozen & Spectrophotometric & Y & $?$ & Y & Y & $\mathbf{Y}$ \\
\hline Particulate phosphorus & 53 & frozen & & $\mathrm{Y}$ & $?$ & Y & $\mathrm{Y}$ & $\mathbf{Y}$ \\
\hline \multicolumn{9}{|l|}{ ORGANIC MATTER } \\
\hline dissolved organic carbon & 53 & filtrated frozen & TOC-V analyser & $\mathrm{Y}$ & $?$ & Y & $\mathrm{Y}$ & $\mathrm{N}$ \\
\hline particulate organic carbon & 43 & Cool, analyse $<24 \mathrm{~h}$ & TOC-V analyser & $?$ & $?$ & Y & $?$ & $\mathbf{Y}$ \\
\hline \multicolumn{9}{|l|}{ SUSPENDED SEDIMENT } \\
\hline Total suspended solids & 24 & Dried filters & weight & $\mathrm{Y}$ & $?$ & Y & $\mathrm{Y}$ & Y \\
\hline Mineral suspended solids & 18 & Dried filters & Ash weight & $\mathrm{Y}$ & $?$ & $\mathrm{~N}$ & $\mathrm{Y}$ & $\mathrm{N}$ \\
\hline Turbidity & 18 & & Cuvette at lab & $\mathrm{Y}$ & $?$ & Y & $\mathrm{Y}$ & Y \\
\hline Secci-depth & 5 & at location & Secci-disk & Y & $?$ & Y & $?$ & $\mathbf{Y}$ \\
\hline \multicolumn{9}{|l|}{$\begin{array}{l}\text { CHEMICAL } \\
\text { CONTAMINANTS }\end{array}$} \\
\hline $\begin{array}{l}\text { UV-screens (oxybenzone) } \\
\text { Heavy metals (Cu, Zn, Ti, }\end{array}$ & 250 & & & $\mathrm{Y}$ & $?$ & Y & $\mathrm{Y}$ & $\mathrm{N}$ \\
\hline $\mathrm{Cd}, .)$. & 150 & $\begin{array}{c}\text { acidified } \\
\text { Frozen passive }\end{array}$ & & $\mathrm{Y}$ & $?$ & Y & $\mathrm{Y}$ & $\mathrm{N}$ \\
\hline PAHs (16 EPA) & 250 & samplers & GC-MS & $\mathrm{Y}$ & $?$ & Y & $\mathrm{Y}$ & $\mathrm{N}$ \\
\hline \multicolumn{9}{|l|}{ MICRO-ORGANISMS } \\
\hline E. coli and other bacteria & 30 & $\begin{array}{l}\text { none, analyse }<8 \mathrm{~h} \\
\text { filter preserved in }\end{array}$ & $\begin{array}{l}\text { agar culture or } \\
\text { enterolert }\end{array}$ & $\mathrm{Y}$ & $?$ & Y & Y & $y$ \\
\hline Virusses, pathogens & 100 & RNA-later & DNA & $\mathrm{Y}$ & $?$ & Y & $\mathrm{Y}$ & $\mathrm{N}$ \\
\hline \multicolumn{9}{|l|}{ BIO-INDICATORS } \\
\hline Chlorophyll-a & 10 & filtration/extraction & Spectrophotometer & Y & $?$ & Y & Y & $\mathbf{Y}$ \\
\hline$C: N$ ration in benthic algae & 10 & freeze-dried & & $\mathrm{Y}$ & $?$ & $?$ & Y & $\mathrm{N}$ \\
\hline algae/marine sediment & 10 & freeze-dried & Mass spectrometry & $\mathrm{Y}$ & $?$ & $?$ & $\mathrm{Y}$ & $y$ \\
\hline
\end{tabular}

\subsection{Application of threshold values}

Environmental threshold values are values that, if exceeded, indicate a potential ecological problem and could trigger a management response, e.g. further investigation and subsequent refinement of the guidelines according to local conditions (Anzecc \& Armcanz 2000). Becking and Slijkerman (2012) described an ecological assessment framework for the Caribbean Netherlands (CN). They referred to the 'European Water Framework Directive' and the 'Marine Strategy Framework Directive' that repetitively endorses the 'stand still' principle, the 'no degradation' principle, and the precautionary 
approach in ecosystem-based management. The stand still principle is also described in 'MilieuNormen Bonaire' (Geleuken et al., 2007) and means that water quality should not recede in time, even when threshold values might not be in sight yet. Although the European frameworks do not apply to the $\mathrm{CN}$, the essence of these frameworks formed the basis for the previous Dutch nature policy in the Netherlands. Therefore, applying the standstill/ no degradation principle is something to consider in the upcoming Water quality program.

For the first interpretation of the monitoring data, it is helpful to have underpinned threshold values for at least the most relevant water quality indicators. Some of these values are already provided in the Nature Environmental Policy Plan (NEPP), and for others, we propose values based on the scanned literature in this brief project (Table 4). Applying the precautionary approach could be considered to use the lowest concentrations mentioned in the literature as threshold levels for this monitoring program.

For chemical substances (metals, PAHs, PCBs), threshold values are not included in the Table. However, they can be found in the literature (so-called Predicted No Effect Concentrations (PNEC) values) for multiple coral species (Ecotox database EPA- http://cfpub.epa.gov/ecotox/).

However, the monitoring should not only be focused on threshold levels. When longer time series become available for water quality indicators, trends in time can be determined to assess how local conditions change due to measures taken.

\subsubsection{Threshold values and limits of quantification}

Each analytical method has a minimum value that it can quantify. This Limit of Quantification (LoQ) is, of course, dependent on the specifications of the equipment that is used for the analyses but also depends on the sample characteristics (e.g. salinity) and/or sample size (see box below for more explanation).

From a scientific point of view, the lowest LoQ is always the best. However, since such high quality has its price, it is wise to define the required LoQ based on the analyses' goal: to provide policy makers with reliable information of sufficient quality to assess water quality related to coral reef conditions. To assess actual levels against threshold levels, selected analytical methods should at least have an LoQ similar to the threshold level but preferably much lower.

\section{Technical background on Limits of Quantification (LoQ)}

Salinity is especially crucial for substances that are measured directly in the water sample, like dissolved nutrients or organic carbon. When high salinity is hampering the analyses, the sample needs to be diluted with demineralised water. Since the detection level of the analytical equipment is set, the LoQ in a saline sample will be higher than in a freshwater sample. In some situations where substances are extracted from the water sample before analyses, like for instance suspended matter that is collected by filtration, the LoQ can be lowered by using a larger water volume for the analyses. In the case of suspended matter; if the accuracy of the analytical balance is $1 \mathrm{mg}, 10 \mathrm{~L}$ of water must be filtered to reach a LoQ of $0.1 \mathrm{mg} / \mathrm{L}$. 
literature.

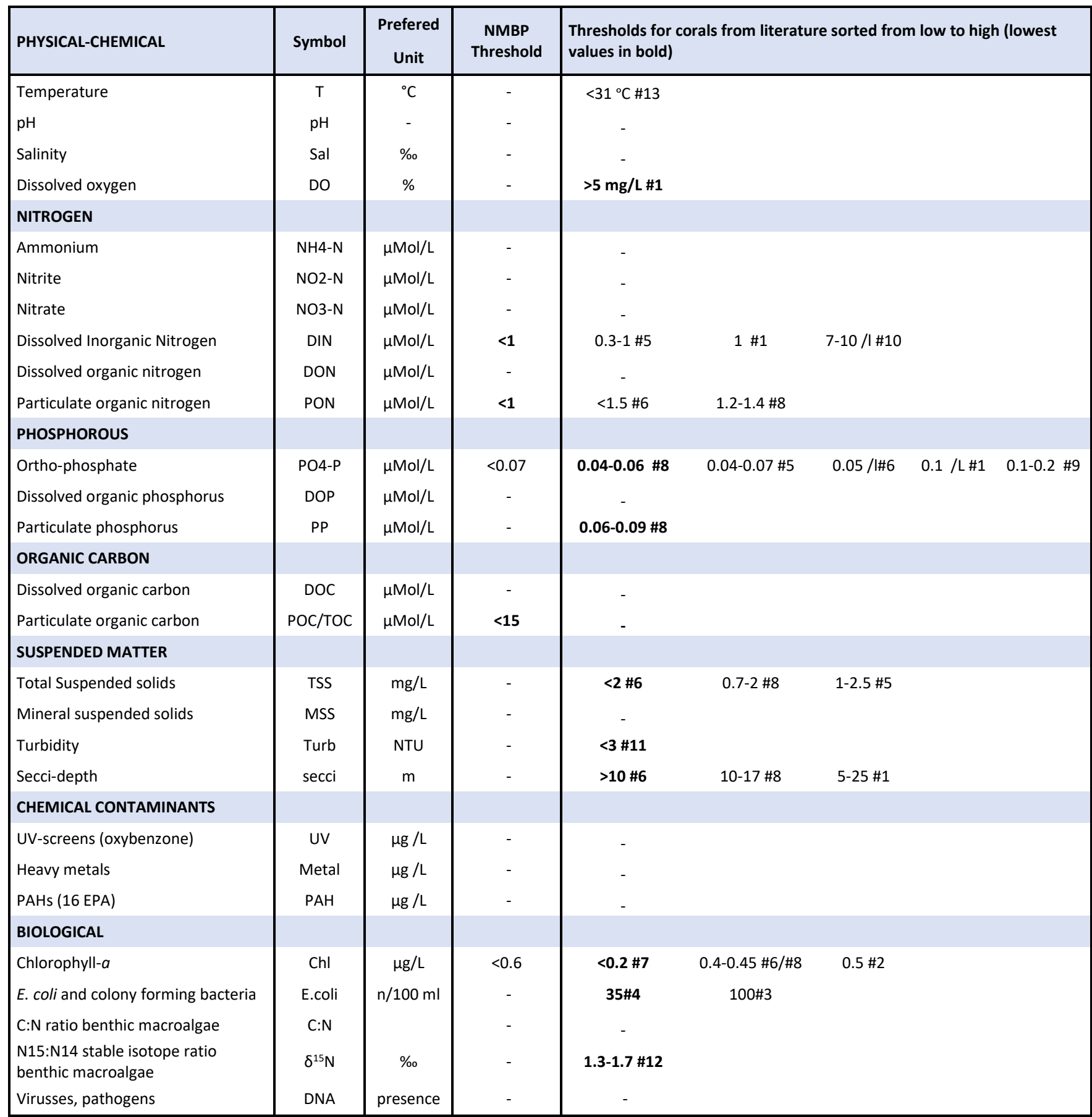

\section{References:}

\#1 Werkgroep Milieunormering Nederlandse Antillen, (2007), which is based on various peer reviewed literature (e.g. Bell 1992, Bell et al, 2007, Lapointe e.a )

\#2 Bell, P.R.F. 1992. Eutrophication and coral reefs-some examples in the Great Barrier. Reef Lagoon. Water Res. 26 553-568.

\#3 Caribbean blue flag (UNEP, 2003)

\#4 US EPA standard (Criteria for Bathing Recreational Waters) (US EPA, 1986)

\#5 Meesters, E.H., Bak, R.P.M., Westmacott, S., Ridgley, M., and Dollars, S. (1998). A fuzzy logic model to predict coral reef development under nutrient and sediment stress. Conserv. Biol. 12(5), 957-965.

\#6 De'ath G, Fabricius KE (2008) Water quality of the Great Barrier Reef: distributions, effects on reef biota and trigger values for the protection of ecosystem health. Final Report to the Great Barrier Reef Marine Park Authority. Australian Institute of Marine Science, Townsville. (104 pp.).

\#7 Lapointe et al. (2007); Lapointe and Mallin (2011)

\#8 MMP Inshore water and coral reef monitoring- Annual Report 2013/14 (Trigger values from GBRMPA 2010 \& DERM 2009)

\#9 Bell et al 2007 Reevaluation of ENCORE: Support for the Eutrophication Threshold Model for Coral Reefs. Royal Swedish Academy of Sciences. URL: https://doi.org/10.1579/0044-7447(2007)36[416:ROESFT]2.0.CO;2

\#10 Houk et al., 2020 Nutrient thresholds to protect water quality and coral reefs

\#11 Cooper et al (2008) Temporal dynamics in coral bioindicators for water quality on coastal coral reefs of the Great Barrier Reef. Marine and Freshwater Research 59(8) 703-716 https://doi.org/10.1071/MF08016

\#12 Waitt Institute (2017) The State of Curaçao's Coral Reefs

\#13 Meesters, E. H. \& Bak, R. P. M. (1993): Effects of Coral Bleaching on Tissue Regeneration Potential and Colony Survival. Marine Ecology-Progress Series 96, 189-198 


\section{Information gathering strategy}

\subsection{Considerations about sampling frequency}

Knowledge of the variability in the water quality of the ecosystem being monitored is fundamental because the degree of variability will determine the final design of the WQ-monitoring program. In addition, it determines the minimum sampling frequency necessary to detect changes (e.g. to detect an effect of the implementation of measures) and the required precision of the instrument or analytical method. Monitoring longer periods (e.g. months to several years) with a relatively high frequency is particularly useful to collect a dataset that allows determining the sampling frequencies needed to make confident interpretations using statistical analysis (i.e., detect daily, monthly, or seasonal variation). However, sampling frequency and period to sample is also a major practical driver of costs and capacity needed (Canadian Council of Ministers of the Environment, 2015).

Long-term water quality monitoring data based on multiple years of sampling are often used to analyse the minimum needed sampling frequency and adapt a monitoring design according to the local variability and objectives drafted. Based on a long-term water quality dataset for the Great Barrier reef (GBR), Bell et al. (1992) advised that chronic eutrophication assessment at the GBR should be based on at least a time series of 30 samples per location taken within at least one year or longer monthly. In the case of the Caribbean Netherlands, there is a lack of long-term monitoring data. The datasets available represent limited monitoring on Bonaire, and for Saba and Sint Eustatius, no data are reported. Other ways to draft a first sampling frequency scheme are needed instead.

Previous monitoring by Slijkerman et al. (2014) and Lapointe and Mallin (2011) revealed spatial and temporal differences, accompanied by occasional eutrophic conditions that might harm the coral reef. However, given the available temporal data (twice a year), whether eutrophic conditions continued in the intermediate months remains unknown. In other words, do these observations represent a chronic or severe eutrophic condition that lasted during weeks/months during and after rainy events or are they only an incidental observation occurring shortly, e.g. after a rain event. An illustration is provided in Figure 4.

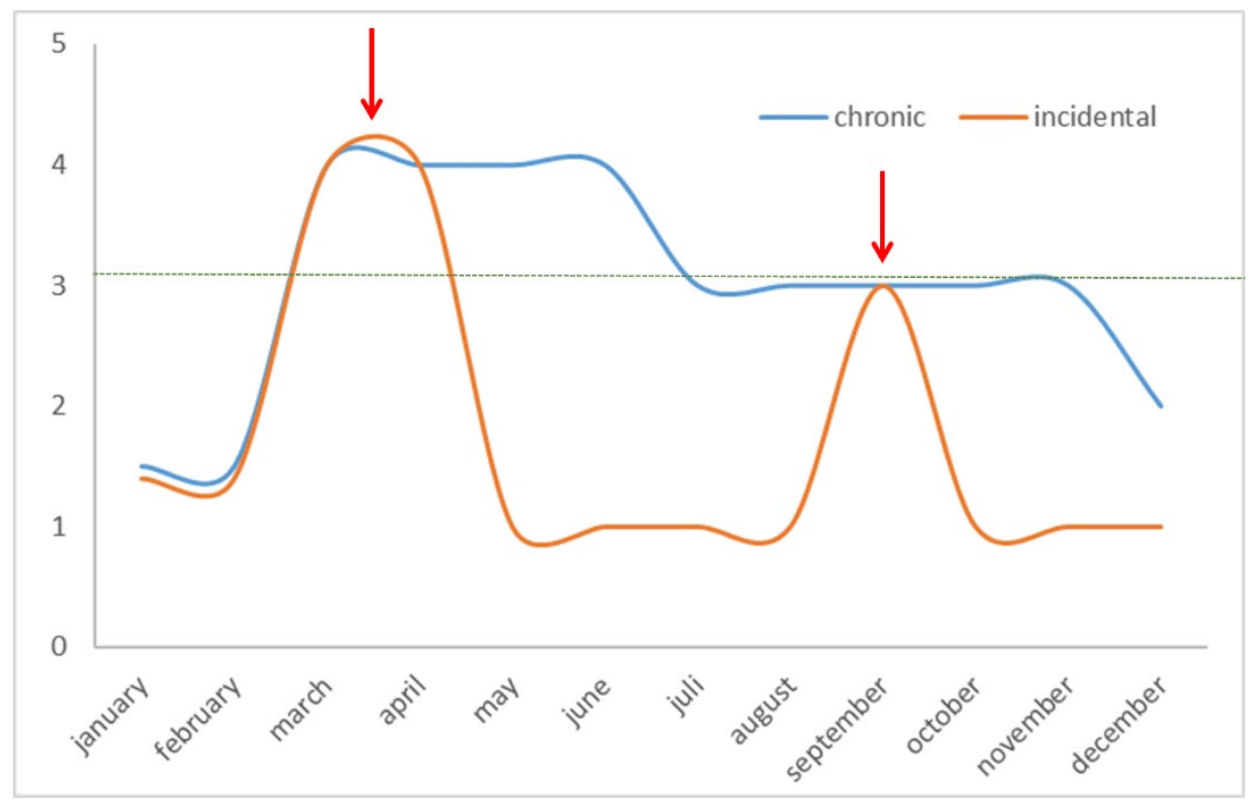

Figure 4 Example illustrates two hypothetical fluctuations of a certain indicator, one representing levels chronically above a threshold and the other incidentally exceeding the threshold. By only sampling two times/year, both the "incidental" and the chronic condition cannot be determined. A consequence could be that additional measures will be implemented or that the reef is impacted more severely as adaptations to pressures are delayed. 
To detect the influence of chronic and incidental conditions, it is advised to initially include a higher temporal resolution in the monitoring program, covering at least two years.

When determining the appropriate temporal aspects of the monitoring, seasonal timing or local trends are important factors to include (CCM, 2015). One should take into account known aspects, e.g. storm-water run-off in the rainy season or fluctuation in high tourist numbers and effects on bathing water near reefs. Monitoring activities should then also be targeted to those particular "aftermoments" that reflect the induced variability in the coastal zone (e.g., sampling for chlorophyll-a or other bio-indicators when nutrient loading is likely, for example, directly after a period with increased terrestrial run-off). One could design and plan these known fluctuations by targeting four important seasonal shifts in a year, as two typical seasons (dry and rainy season) result in four alternating circumstances. However, besides known trends in time, one should also take into account a specific frequency to detect yet unknown patterns. A minimum of four times sampling per year could miss out on important observations. Also, the chronic versus the incidental state of impacts cannot be evaluated through a "four times per year" interval. A monthly interval is then an alternative frequency that will provide a long-term monitoring data set that can be used to adapt the monitoring design according to the assessed variability. Calculating the necessary number of samples to detect a certain amount of change with sufficient power would also be necessary.

\section{Technical background on number of samples and precision}

The number of samples required to achieve a certain monitoring precision depends on the variability of the water quality variables measured. The greater the variation of the water quality variable, the greater the number of samples needed to obtain a statistically sound estimate. By increasing the number of samples, a reduction in the standard error of the mean value of the water quality variable can be achieved. Basically, the range in which the mean value lies becomes smaller and the mean more precise. Since the standard error of the mean is inversely proportional to the square root of the number of samples, an increase in the number of observations will consequently lead to an overall gain in the precision of the results. A commonly used method to determine sampling frequencies is the use of power analysis in which the number of samples is determined based on the variation in measurements, the effect size, and the amount of confidence one would like to have in a comparison.

\subsection{Considerations about sampling locations}

\subsubsection{Surface water}

Depending on the goal of the monitoring, it is necessary to consider the position of the different samples. Along the coastline of any island, there are a lot of differences that may influence water quality measurements. For example lack of vegetation in a catchment area may lead to increased runoff and turbidity of the water. The presence of a city can lead to eutrophication. Spatial variation is important because it may lead to increased variation in the measurements, influencing the power to detect differences over time or between areas. To say something about the status of the water along the coast of an island, it is not sufficient to measure only at one point. Currents flow along an island and are often uni-directional at the islands of the Caribbean Netherlands most of the time. For Bonaire, the main current generally flows from the southern tip of the island to the north. Where the oceanic waters reach the island, water quality will be different from where the water leaves the island, while the water quality can be affected by activities and events that happen on land.

Another point to consider concerning water quality is water depth. Coral reefs can generally be found in shallow waters down to a depth of approximately 60 meters. Often water coming from the island has a lower salinity than seawater and, consequently, will float. Surface water will therefore have different characteristics than deeper water, which may result in depth-dependent nutrient concentrations. To get an idea of the spatial variation of each indicator, it is, therefore, necessary to sample at many points along the coast and different depths. Once it is clear how spatial variation is structured, it may be possible to generate distribution models and decrease the number of sampling locations. 
One should realise that the coastal water is part of a dynamic system in which island-based contaminants can be rapidly diluted and transferred to other/deeper areas. In addition, dissolved nutrients will be assimilated by biota and thus disappear from the water. As a result, contaminants discharged into coastal waters are sometimes difficult to measure, and in most cases, challenging to trace back to a specific source.

\subsubsection{Groundwater}

Groundwater is considered a major source of contaminant input to coastal waters on the BES islands. Therefore, monitoring groundwater quality is likely to be an effective method to get insight into landbased contaminant fluxes towards coastal waters and determine the effectiveness of relevant inland policy measures.

In 2012, 32 monitoring wells were installed on Bonaire, used to sample the groundwater in November 2012 (Progressive Environmental Solutions, 2013). In March 2016, not all of these wells were present or locatable anymore, but groundwater samples could be collected from 26 locations (Arboleda \& Peachey, 2016). The most notable observations were the extremely high densities of faecal bacteria found at several locations and the significantly lower $\mathrm{pH}$ of groundwater in 2016 compared to 2012 (Arboleda \& Peachey, 2016). The analytical results did show significant differences between sample locations that were not consequent for the two sampling years. The correct interpretation of the sampling data requires insight into the factors that influence groundwater composition at the sampling sites. The composition of the groundwater is influenced by natural factors such as (local) precipitation, daily tides, and season-dependent high water levels (Progressive Environmental Solutions, 2013). Without being experts on this, we assume that the salinity of groundwater is a good indicator of the mixing with coastal water, provided that there is no brine discharged in the area. We also assume that the water level in the well relative to sea level is an indicator of pressure/flow towards coastal waters. These things can be determined relatively easily and without additional cost using a salinity meter and a dipstick. Therefore, we think it would be useful to measure salinity and water level for a year for each still available well, for example, bi-weekly. This data should then be combined with information about tide/water levels at the time of measurement and precipitation or local irrigation during the preceding period. It seems likely that in this way, at a relatively low cost, insight can be gained into the extent to which well is affected by these conditions and where/when mixing with coastal water occurs. Based on this, wells can be selected that provide the most relevant information for assessing the effectiveness of policy measures' effectiveness and their effect on coastal water quality. These monitoring wells can then be included in a regular monitoring program. The initial focus should be on analysing total nitrogen and bacterial concentrations as proposed by (Progressive Environmental Solutions, 2013) because these parameters indicate pollution with wastewater. In addition, standard and cheap analyses like salinity and $\mathrm{pH}$ should be included.

\subsubsection{Run-off water}

Run-off water forms another known source of contamination of coastal waters. Depending on the location, run-off water can carry suspended organic matter, sediment, nutrients, pollutants and agricultural chemicals. Therefore, we suggest installing pits that collect storm water at locations where run-off water reaches the coastline. These pits could be used to collect samples during or after a rainy period, and when the water volume is logged, they could maybe also indicate changes in the volumes of run-off water over the years.

\subsection{Semi-continuous and time-integrated measurements}

As the previous paragraph indicates, sampling frequency is an important issue and (semi-) continuous sampling should be preferred. However, at this moment (semi-) continuous sampling is not possible for all indicators of interest. Apart from technical aspects that do not allow all indicators to be measured continuously, the accuracy and the low limits of detection that can be achieved with 
traditional water analysis techniques are not always reproducible in (semi-)continuous monitoring. Nonetheless, several options exist that can add value to the WQ-monitoring programs that are the subject of this framework. These will be discussed in the following paragraphs.

\subsubsection{Semi-continuous measurements}

Some environmental indicators can be measured directly in the water column using instruments/probes, allowing for semi-continuous monitoring of these indicators. Water temperature, $\mathrm{pH}$, salinity, and light penetration are examples of indicators that can be logged at fixed positions using in situ sensors at a fixed position (e.g. on buoys) or on ships (e.g. ferrybox). With time, the sensors will be overgrown by algae and other benthic organisms and thus need to be cleaned at regular intervals to obtain accurate measurements. Water temperature and $\mathrm{pH}$ are important climate change-related water quality indicators for the local conditions for coral reefs. For example, monitoring salinity and light penetration depth might reveal an influx of fresh water and water with high sediment loads, respectively, caused by a run-off event during heavy rainfall. Even when these indicators are not the most indicative for the major pressures on coral reefs in the Caribbean Netherlands, they may show daily or hourly patterns that are overlooked when sampled monthly. These patterns might reveal specific occurrences that require adaptations in the monitoring scheme.

The possibilities of remote sensing (RS) for, among others, water quality monitoring in the Caribbean Netherlands islands are described by Blauw et al (2020). Turbidity, chlorophyll-a concentrations, the presence of oil slicks, and the occurrence of pelagic Sargassum seaweed are listed as optional indicators. Critical aspects of the application of remote sensing are limits of detection and spatial and temporal resolution. Regarding the latter, it should be noted that weather conditions may hamper the applicability of RS for determining the impact of run-off in the Caribbean Netherlands, as clouds develop early in the morning above tropical islands and frequently hamper the usefulness of satellite data. Especially during the rainy season, this could decrease data coverage when run-off takes place, even with the 5-day return frequency of the new Sentinel satellites.

The relatively low spatial resolution of (freely) available remote sensing data limits the applicability of RS to detect local pressures. However, when paid for, RS-data with a higher spatial resolution is available.

An option suggested by Blauw et al (2020) is to use the (free) data from Sentential-2 on chlorophyll concentrations (indicative for algal biomass) and turbidity with a spatial resolution of 10-60 $\mathrm{m}$ and a 5-day frequency. Such a dataset could indicate if and where turbidity increases during/after intense rain events and if algal biomass is higher in the neighbourhood of known or suspected sources of nutrients. However, cloud formation will strongly limit the applicability of these data (with a 5-day return, there are often not more than 2-4 cloudless images for Bonaire in one year). Therefore, the RS data should always be validated with field measurements, especially in relatively shallow clear water where the colour of the seafloor can hamper accurate measurements of the water column. In addition, it should be established whether the 'analytical resolution' is sufficient to identify the changes in water quality that can be expected. If this is the case, RS with a larger spatial resolution can show how ocean currents are affecting the coastal water quality of the Caribbean Netherlands islands. Blauw et al. (2020) also indicate the potential of RS for ecological monitoring, but that is beyond the scope of this framework.

\subsubsection{Time-integrated measurements and bioindicators}

The above mentioned methods all have in common that they provide a snapshot, a measurement or image at a particular time. By increasing the frequency of sampling, more information about temporal patterns in water quality can be achieved, but for indicators that do not (yet) allow continuous monitoring, accompanied by increased costs and effort. For a limited number of indicators, methods are available where a single measurement provides information about environmental conditions over a longer period, so-called time-integrated measurements. For example, polycyclic aromatic hydrocarbons (PAHs) are indicators for pollution with oil compounds that are believed to be severely toxic to developing corals (Hartmann et al., 2015). For determining the presence of PAHs in the water column, effective time-integrated sampling techniques are available in silicone rubber sheets exposed in the water column. During exposure, these sheets absorb poorly water-soluble substances (like PAHs) from the water. After exposure for weeks, chemical analyses of these sheets will provide a 
time-integrated picture of $\mathrm{PAH}$ exposure, including the impact of temporarily peaks that might have occurred during occasionally spills.

Bioindicators can also provide an integrated description of environmental pressures over a specific period. Bioindicators are responses in or by (parts of) living organisms such as corals, plankton, macroalgae that can be used to assess the health of an ecosystem (Parmar et al., 2016). Any resulting changes observed in bioindicators are thus a (net) result of ecologically relevant changes in environmental conditions such as water quality plus ecological feedback loops (Fabricius et al., 2012). Efficient time-integrated sampling to detect the presence of land-based nutrients from sanitary wastewater is possible by analysing the ratio of stable nitrogen isotopes in benthic macroalgae or marine sediments collected at the sampling points. The Waitt Institute has demonstrated its value for Curaçao's Coral Reefs (2017). Tissues of benthic macroalgae or seagrasses can also be analysed for their $\mathrm{C}: \mathrm{N}$ ratio, a time-integrated indicator for nitrogen availability in the weeks before sampling. Local benthic algae can thus be used as a time-integrated bioindicator for eutrophication caused by high nutrient influx (pressure). The presence of intestinal micro-organisms like E.coli or Enterococci can serve as a bioindicator for sanitary wastewater. Relevant bioindicators for land-based sediment run-off towards the reef have not yet been identified. However, van der Geest et al. (2020) found a strong negative correlation when linking erosion risk on land with down-stream sand cover at the leeward reefs of Bonaire, suggesting that sand cover at the reef may be suitable as a proxy for land-based sedimentation at the reef, particularly when combined with nitrogen stable isotope analysis of terrestrial and marine sediments.

\subsection{Sampling strategies}

In this paragraph, we describe three sampling strategies. These strategies will be discussed in the NEPP Steering Committee, after which one of these strategies will serve as the basis for an operational plan for the monitoring of the water quality, tailored towards the specific needs of Bonaire, Sint Eustatius and Saba.

The first two strategies aim at monitoring the water quality as it is experienced by the coral reefs, thus in the coastal surface waters around the islands. The advantage of these approaches is that the monitoring results directly reflect the local environmental conditions for the corals and can be compared with the threshold levels presented in Table 4. However, the drawback is that due to the variability of the coastal environment, a comprehensive monitoring program is required, with high numbers of sampling locations that should be visited multiple times per year. Below, such a comprehensive strategy, but also a less intensive, hence cheaper strategy are presented.

In addition to these strategies that focus on monitoring surface water quality, a suggestion is made for a more pragmatic approach to monitor the effectiveness of the measures in the Action Plan aimed at improving the water quality. Here, the monitoring effort mostly focuses on the major causes of poor coastal water quality: groundwater and run-off water. The advantage is that the quality of ground and run-off water can more easily be linked with pressures and is more directly influenced by measures than surface water quality. Moreover, concentrations of target substances (nutrients, bacteria and suspended particles) will be much higher before than after being diluted in the coastal zone. This means that less sophisticated analyses are needed to collect the data. However, the drawback is that the monitoring results serve only as a proxy for island-based pressures on the coastal water quality.

The best option seems to combine a yearly monitoring of ground and run-off water (pragmatic approach) and biological monitoring of benthic cover (e.g. coverage of sand, cyanobacterial mats, macroalgae) with more or less intensive monitoring of the coastal water at a less regular basis for instance three years.

\subsubsection{Sampling strategy for monitoring surface (coastal) water quality}

This section will present an intensive and minimum sampling strategy to monitor coastal water quality. The intense strategy (strategy 1 ) provides more spatial and temporal detail but is costly and asks for 
capacity that is not yet in place (remarks made in stakeholder meeting 2). Strategy 2 describes an alternative strategy in which a minimal temporal scale is presented, and alterations are made in the number of samples collected per position and include a minimum set of indicators. Intermediate scenarios are possible but not elaborated on in this report.

Ideally, the WQ-monitoring program starts with an intensive sampling strategy to assess spatial and seasonal variation, which will be evaluated after six months, one year, and two years. During the evaluation, the different sources of variation need to be assessed; power analyses need to be performed for each indicator, after which the sampling design will be optimized. Optimization may mean a change in sampling frequency and/or locations.

Each island should identify locations and indicators wisely to be cost-effective. For example, sunscreen ingredients or PAHs are costly to analyse, and in addition, they are strongly related to specific sources. Therefore sampling of PAHs should be limited to locations and situations where it is considered relevant.

The presented strategies mainly collect data from discrete water samples, except analysis of benthic macroalgae for nitrogen stable isotope ratios, which is a time-integrated indicator for eutrophication. However, at locations that are expected or known to be critical for changes in water quality, continuous sampling of water characteristics like salinity and/or light penetration depth is useful to add.

In addition to in situ measurements, remote sensing data on chlorophyll-a and suspended matter concentrations can be useful to get a background picture of water quality conditions in the wider Caribbean, for instance, for suspended matter or algal blooms, originating from the discharge of large rivers in South America (e.g. the Orinoco).

For all measurements, it is essential that the accuracy is sufficient and that precision is high enough to identify an agreed-upon level of change.

To describe the spatial distribution of where sampling takes place, we use the terms Island, Location, Sample Point and Sample Depth, as illustrated in Figure 5.

\subsubsection{Comprehensive sampling strategy for surface (coastal) water quality}

The 'intensive strategy' provides detailed spatial and temporal coverage for all indicators mentioned in the longlist (Table 4). Data analyses can reveal a correlation between indicators, depths, locations and time of the year. Drawbacks are capacity needs for sampling and sample handling at this intensity. Islands probably need additional sampling and technical capacity, and financial support to be able to organise this. 


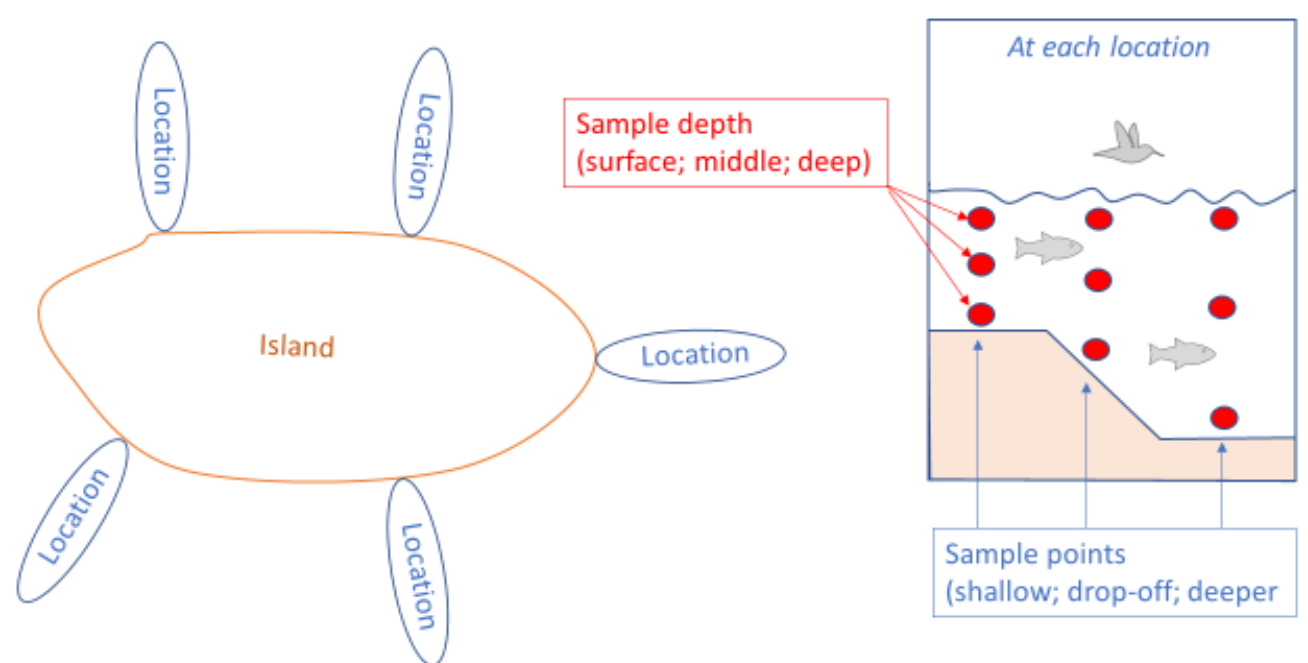

Figure 5 Presentation of the terms, Island, Location, Sample point and Sample depth, used in this framework to describe the spatial distribution of where sampling takes place. This is just a schematic presentation, the exact (numbers of) locations are to be filled in in the operational plan that is tailored towards the specific needs of the island.

\section{Sampling locations}

As described in the goal definition, monitoring should take place in the marine park at multiple locations. Therefore, an intensive scenario should include the following range of locations and:

- A coverage in locations that include coral reefs in different biological conditions (e.g. coral health, cover and diversity), thus including both good/better and deteriorated sites*.

- A coverage in locations based on expected and known pressures. These may well overlap with the former type of locations.

- At each location: a transect from the coast to deep water covering 3 Sample points: shallow reef, drop-off and deeper reef, with in total 3 sample depths at each of these points:

- 0.5 meters above the reef/bottom

- Mid water depth

- $30 \mathrm{~cm}$ under the surface

Each sample point and each sample depth is first sampled in Duplo to get a feeling of variation. This will result in 18 water samples per position. If there is minimal variation between samples, replicates per depth can be skipped.

* In addition to the range of coastal positions that will be included, we also propose to include two offshore locations that can serve as a reference for ocean water without being affected by the islands. Here, only water samples have to be collected near the water surface.

\section{Sampling frequency}

A relative high sampling frequency of about once a month is preferred at the start of the monitoring program for about two years, as it gives a good insight into temporal/seasonal variation.

\section{Analytical costs}

This intensive strategy results in $(12 * 18=) 216$ nutrient samples per location per year and $(4 * 18=) 72$ samples for chemical sampling per selected location per year.

As indicated in Table 3, the analytical cost per sample to analyse the proposed indicators related to wastewater and run-off is approx. $~ 520$ euro/sample. The analysis of the set of chemical contaminants costs 
650 euro/sample. A monthly sampling of nutrients and quarterly sampling of chemicals in duplo correspond with an estimated analytical cost of $\sim 21000$ EURO/location and a total of 153000 EURO/location/year.

This amount is for analyses only and excludes sampling time, person-hours and equipment, sample handling in the lab, storage and transport.

It should be emphasized that this cost estimate is only very rough, and it is, of course, possible that lower prices can be negotiated if the analyses of all the samples are contracted out for a more extended period.

We propose monitoring the water quality indicators presented in the longlist and then evaluating the usefulness of the set of indicators and spatial and temporal dimensions at set points in time $(6,12,24$ months). Based on the results of this first year to the best value for money/effort selection can be discussed. It is expected that several indicators will be strongly correlated. Depending on the outcome, a smaller or larger selection can be made. The evaluation criteria are listed in section 8.1.

\subsubsection{Less intensive sampling strategy for surface (coastal) water quality} This scenario provides a brief but limited overview of water quality data. An advantage is that the costs per location/year are much lower than the intensive strategy and that capacity needs (men hours) are decreased significantly. A disadvantage is a somewhat limited overview of water quality and the possibility of missing relevant locations and/or events, resulting in limited or no statistical power to assess the effectiveness of measures.

\section{Sampling locations}

All of the above-described aspects apply to cover a wide range of locations, but adaptations are made at the sampling position by discarding the deeper reef and mid-water samples (Figure 6). However, this would still give some idea of the extension of water quality effects at different depths, at different distances from the coast, and along the coast.

This strategy results in 4 sample points per location, hence eight samples when sampled in Duplo.

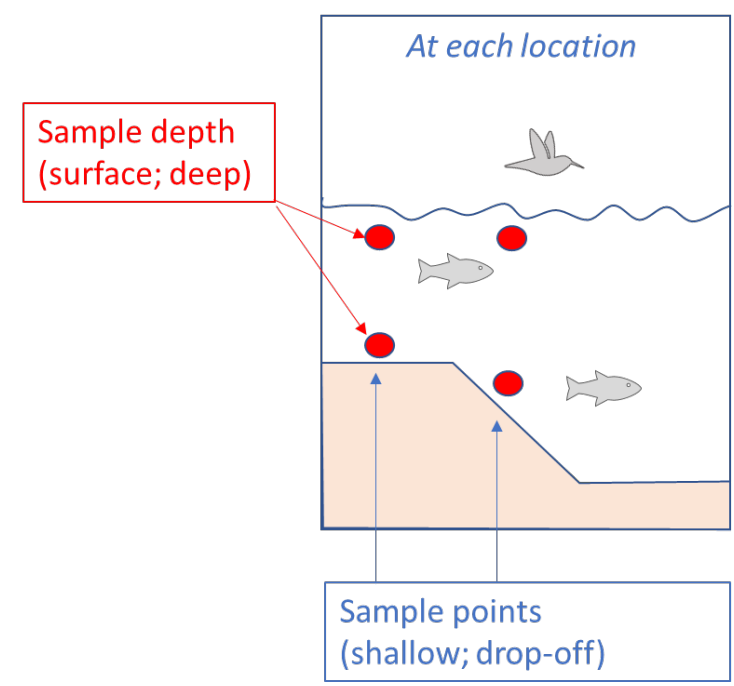

Figure $6 \quad$ Illustration of where sampling takes place in the minimum sampling strategy scenario

\section{Sampling frequency}

A minimum sampling frequency should cover at least the important seasonal changes; this implies the dry and the rainy season.

Also, in this minimum strategy, additional sampling should be added at moments that are relevant for specific pressures, like during:

- tourists seasons

- $\quad$ periods of heavy rainfall (pulse disturbances)

- moments of industrial discharges

Assuming one such additional sampling event per year and sampling events during the dry and rainy season, the minimum sampling frequency will be three times per year. 
In this minimum design, we propose to focus on those indicators for which a threshold level is known (see table 4). This includes a selection of nutrients and bioindicators. In addition, the physical indicators can easily be measured during the sampling at low additional costs and thus are also included.

With this minimum set, the water quality can be assessed against critical levels. Potential underlying relations between discarded indicators and the remaining set can, however, not be tested. The estimated cost for analysis of this minimum set of indicators is $\sim 338 €$ per sample.

Elevated concentrations of various pollutants are observed in the Caribbean at harbours, industrial areas, and discharge points and can be above environmental risk levels, suggesting the existence of environmentally damaging situations (Fernandez et al., 2007). Despite these concerns, we suggest including in this minimum set, only those indicators that are linked to certain activities and pressures and have proven to be harmful to corals in the field situation at relevant exposure levels.

At suitable locations, we propose to include sampling for PAHs for the following reasons. First, PAHs are linked to shipping and oil terminals, both activities present at the islands. Oil-contaminated seawater (of which PAHs are the main components) in the coastal zone of Curacao is known to reduce the settlement of juvenile corals up to $85 \%$, being even more severe than direct effects on survival (Hartmann et al., 2015). Based on these observations, we suggest including PAHs for those field locations for which PAH's are relevant (e.g. near/upstream of oil terminals). It is advised to sample PAHs using passive samplers (see chapter 6.3.2). The analytical costs per sample for $\mathrm{PAH}$ are $250 €$ resulting in $583 €$ per location per sampling moment.

We advise excluding analyses of oxybenzone and metals (at this moment). However, a risk of oxybenzone to coral is suggested based on risk assessment studies and laboratory experiments (Schaap and Slijkerman et al.,2018; Wijgerde et al., 2020) not proven yet in the field situation. For metals, no explicit reference is found for coral reefs yet.

\section{Analytical costs}

This minimum sampling strategy results in 24 samples/location/year (based on eight samples per location * 3 per year). When analyses are limited to nutrients and bioindicators with known threshold levels, the analytical costs per sample are estimated at $€ 338$. The estimated analytical costs are then $€ 8112$ for 24 samples /location/year when samples are collected and analysed in duplo. These costs can be reduced by $50 \%$ to ca $€ 4000$ if only one sample is collected per sample point (12 samples per location/year), but then information about the accuracy of the data will be lost.

As indicated above, it is advised to include analyses of PAHs at specific positions, which will add $€ 250$ to the analytical costs of these samples.

The above costs are for analyses only and exclude sampling time, person-hours and equipment, sample handling in the lab, storage and transport. It is also excluding the costs for rapid response sampling and analyses.

After two years, the dataset can be evaluated, and adapted costs/sampling locations are considered.

\subsubsection{A pragmatic strategy for monitoring effectiveness of measures}

Monitoring the quality of groundwater and run-off water is probably the most effective way to assess the effectiveness of the policy measures that should reduce the emission of pollutants to the coastal zone via these pathways. The number and location of the sample positions (i.e. groundwater wells and run-off pits) strongly depend on the local situation and should be tailored by experts for each island. 
Below, a brief and incomplete suggestion for this pragmatic strategy is given, based on information about groundwater (sampling) kindly provided by an expert from Deltares, and some creative gut feeling of the authors of this report, not being experts in this field.

\section{Groundwater monitoring}

Changes in groundwater quality can best be monitored by sampling the freshwater lens's surface ( $1 \mathrm{~m}$ depth). For this monitoring, wells should be placed at positions selected by experts based on the local situation and the local land use and the expected impact of policy measures. Due to limited mixture and movement, groundwater quality is relatively stable over time, and sampling frequency can be limited to once a year. The initial focus should be on analysing total nitrogen and bacterial concentrations as proposed by (Progressive Environmental Solutions, 2013) because these parameters indicate pollution with domestic wastewater, which is harmful to coral reefs.

\section{Run-off water monitoring}

To monitor run-off water quality during the rainy season, it could be an idea to install pits at positions where run-off to the coast water is known to occur. These pits protected from direct rainfall should be emptied and cleaned at the start of the rainy season. Then, the run-off water collected in the pit can be sampled (after proper mixing to resuspending particles) several times during the rainy season. Analyses should focus on nitrogen, phosphorous and particulate matter. In addition, at relevant locations, bacterial concentrations (indicative for human or animal faeces), agriculture chemicals, or other specific chemicals (e.g. PAHs in case of potential oil spillage in the neighbourhood) could be included.

\subsubsection{Analytical costs}

An overview of estimated analytical costs for each sampling strategy is presented in Table $\mathbf{5}$ per sampling location. 
Table 5 Overview of estimated analytical costs for the three sampling strategies eventually expressed as costs per location per year. Note that the number of locations to be sampled is Island- and strategy-specific, and for that reason, a direct comparison between the strategies based on coastal water and ground/run-off water is not valid. The frequency of run-off water sampling depends on weather conditions.

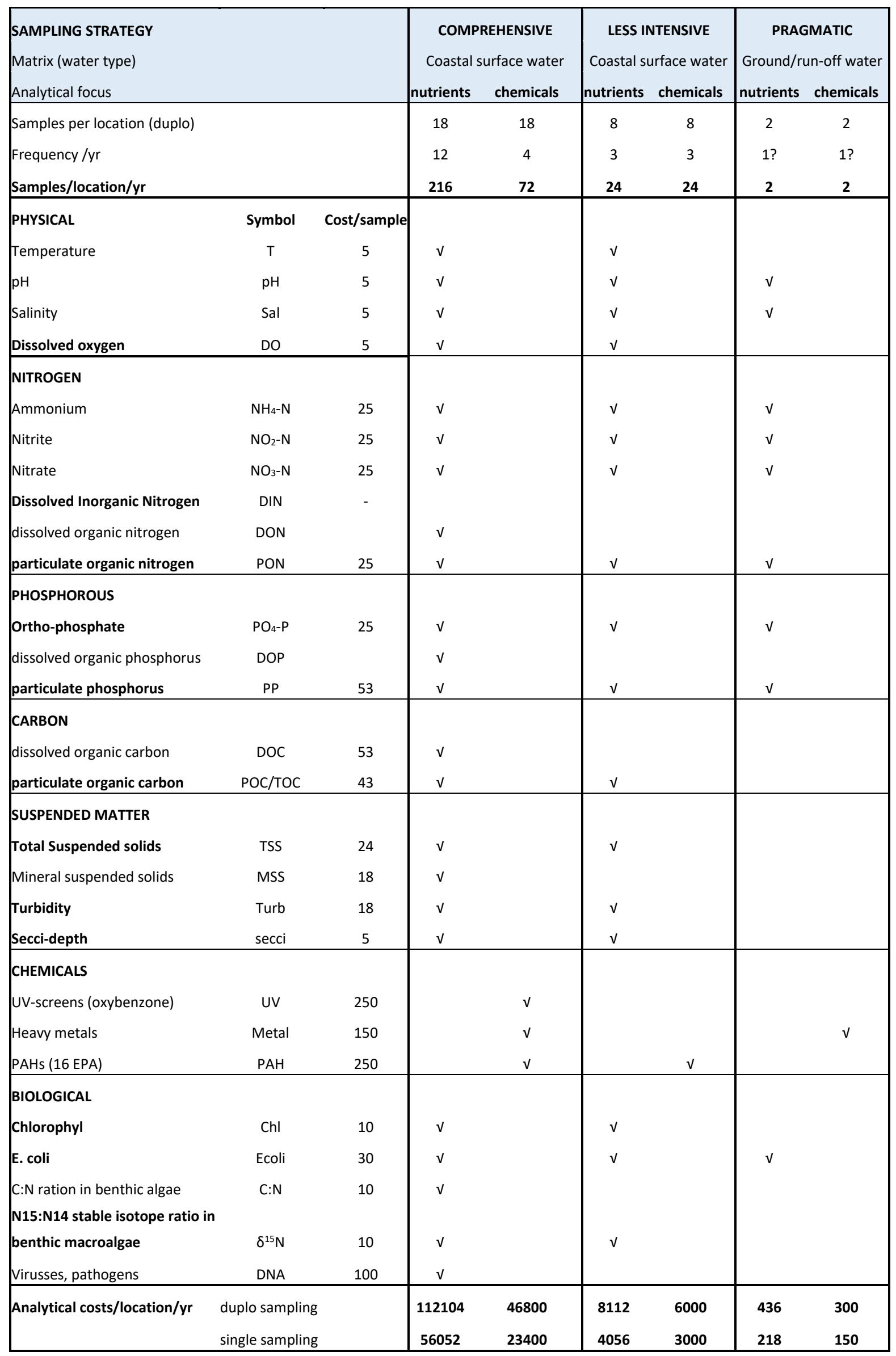




\subsubsection{Capacity needs}

Costs involved for sampling, handling, storage and transport of samples are estimated per island by the involved parties. The costs cannot be specified per scenario due to unknowns related to local possibilities, dependencies, capacity, and choices to be made. For instance, the spatial scale of the three islands differ, and sampling by boat on Saba and Sint Eustatius might take less time than on Bonaire. However, circumstances/weather conditions (wave exposure) might be more challenging on Saba and Sint Eustatius than Bonaire, and therefore the time needed for sampling per location might be higher at these islands. The choice on how to sample water results in different capacity needs such as skills and equipment needed. Sampling using Niskin-bottle sampling or SCUBA requires different skills and equipment. E.g. Niskin-bottle sampling does not require skilled scuba divers and surface time for divers.

According to the 'Pragmatic strategy', sampling can be done from land that is more efficient and less affected by local circumstances and conditions than collecting water samples from a boat.

The number of sampling sites in water or on land, their location, way to access, and a subsequent smart logistic plan will result in the required capacity and equipment needs. However, since these plans have to be defined by the stakeholders, a specification per island cannot be provided yet.

In the section hereafter (6.4.4.1), generic skills and education level is drafted by which the involved parties themselves can evaluate the needed additional capacity building. 


\subsubsection{Generic staff description for complete monitoring incl. analysis and data evaluation}

Technical plan + coordination

- Coordinator. Scientific/higher educated person

- Lab technician: a higher educated person

\section{Sampling and sample preparation}

- Car or boat driver (any)

- Coordinator. Scientific/higher educated person

- $\quad$ Lab technician (mid/higher education)

Sample analysis:

- Lab technician (higher education)

Data evaluation and reporting

- A scientist with (multivariate) statistical skills

- Power analyses

- $\quad$ Specialist sampling design

Some functions can overlap; the car and boat driver and lab technician could be the same person, and a coordinator with statistical skills can also evaluate and analyse the data and write the report. 


\section{$7 \quad$ Capacity and Regional cooperation}

\subsection{Technical requirements}

In this assignment, the authors presume that the execution of sampling, sample preparation, storage and data evaluation is done as much as possible by local organisations and their staff.

Since the capacity on the islands is limited, hardware to store and analyse samples might not be available. Also, in the Netherlands, this equipment is scarce and not available in smaller municipalities. To meet the threshold levels for nutrients in coastal surface water, costly equipment and only available in a few institutes/laboratories in the Netherlands is required. In groundwater, higher nutrient concentrations can be expected, while the salinity will be much lower than coastal surface water. Therefore less sophisticated analytical equipment is required for the analyses of these samples. Also, the available personnel capacity on the islands may be limited in some cases.

The technical requirements for each phase are:

\section{Preparation}

- Determining who does what and when, and who is in charge.

- Capacity building on the islands. Training or hiring/appointing technical and scientific staff, to execute sampling, sample processing and data analyses.

- L Linking and matching reef monitoring (ecology) to water quality monitoring (environment) and pressure factor monitoring in space and time as much as possible.

- Inclusion of local variations: particular sampling locations with particular pollution (coastal development, run-off, discharge, saliña's, brine water) and inclusion of reference sites.

- Defining relevant seasonal dynamics and integrate them into a strategy.

- Drawing up protocols for sampling, reprocessing, storage, transport and analysis.

- Drawing up protocols for the elaboration of data and information-exactions.

\section{Execution:}

- Sampling and reprocessing of samples taken in coastal waters is carried out by local parties and experienced/trained persons.

- Samples taken can be stored and (if necessary) sent out under prescribed quality requirements for analysis elsewhere.

- Analyses should be traceable, reliable, reproducible and with the correct detection limits.

\section{Data processing information extraction}

- Data should be stored centrally and securely. 


\subsection{Cooperation}

Local cooperation is required in the development of local analysis capacity, possibly sample storage. Regional cooperation can be beneficial for the acquisition and reprocessing of remote sensing data (wider than just water quality parameters). Options for collaboration mentioned during a stakeholder session are listed in Table 6

Table 6 Options for collaboration mentioned during a stakeholder session

\begin{tabular}{|l|l|}
\hline Stakeholder & Expertise/equipment \\
\hline & \\
\hline CARMABI- Curaçao & Capacity building/analyses/design program \\
\hline Ross University- St Kitts & DNA/RNA lab- diseases \\
\hline LBS protocol members (check ratification by RWS) & Monitoring of LBS criteria \\
\hline
\end{tabular}

A list of regional marine laboratories is given in annex 3. These are members of the Association of Marine Laboratories of the Caribbean. The list of institutes could be screened and contacted in the next phase to investigate if the laboratories can meet the requirements. For practical reasons, laboratories at locations with good airline connections to the islands should be preferred. 


\subsection{Information gathering strategy and criteria for evaluation}

We recommend starting the water quality monitoring with a broad set of indicators at high frequency and high spatial coverage. In the same period, remote sensing data should be collected close to the moments when the samplings are being performed. This will validate the data collected by remote sensing and assess the added values for the WQ-monitoring program.

The WQ monitoring in the coastal zone can best be combined with monitoring near coast groundwater stations at selected locations that can give a more direct picture of the effectiveness of the policy measures on the islands. Ideally, monitoring the state of the reefs (e.g. coverage of sand, macroalgae, cyanobacteria) and pressures (erosion, wastewater, pollution and algal blooms) are performed in parallel. Spatial and temporal scales should be aligned but adjusted according to the indicators selected within those programs.

Once the data set is available after the first year of monitoring, and evaluation is advised based on the following criteria:

\section{For each Indicator:}

- Specificity, Variability, Practicality, Relevance, and Evaluation (see Table 1).

- Power analyses to determine what sample frequency is needed to detect a relevant change in this indicator.

- Correlating indicators, correlations can be expected between, for instance, particulate organic matter and particulate organic nutrients; if such a correlation is strong, select the indicator that is the most reliable and less expensive.

- Correlation with remote sensing data to check if remote sensing observations can replace parts of sampling and analysis.

- For interpretation of the data it is essential also to monitor local weather conditions.

For sampling locations:

- Analysis of spatial correlations between sample locations to determine how many sites should be sampled in space.

- Identify sampling locations that are most indicative of the local situation.

- Identify sampling locations that are most indicative of the impact of local drivers and pressures.

\section{For timepoints:}

- Identify the seasonal pattern to select the important timepoints to see the impact of local drivers and pressures.

- Identify the seasonal pattern to select the timepoints when conditions for coral are most critical.

- $\quad$ Correlate indicator data with weather conditions to identify critical periods.

Based on these insights, the WQ-monitoring program can be tailored to the most cost-effective strategy. It is recommended to integrate and evaluate the collected data regularly to keep track of changing situations, check if new more accurate or more cost-effective monitoring techniques have become available, or evaluate measures taken (Figure 7). 


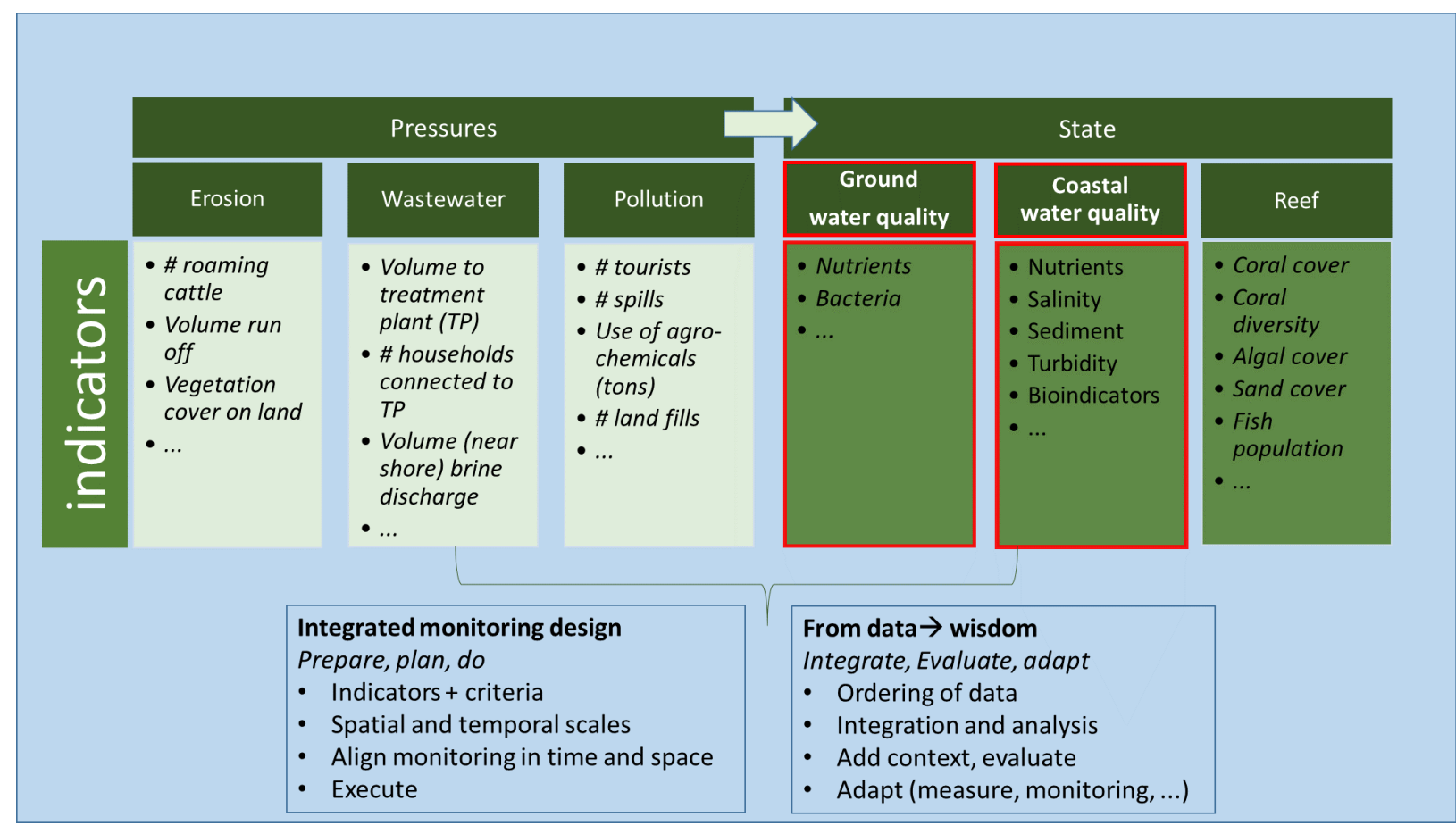

Figure 7 Scheme summarizing the integration of water quality monitoring into an overall ecosystem monitoring design in which pressure and state monitoring are aligned and evaluated together. The red boxes indicate the aspects that were part of this report. 


\section{Quality Assurance}

Wageningen Marine Research utilises an ISO 9001:2015 certified quality management system. This certificate is valid until 15 December 2021. The organisation has been certified since 27 February 2001. DNV GL issued the certification. 


\section{References}

Anzecc \& Armcanz (2000) Australian and New Zealand guidelines for fresh and marine water quality. Volume 1, The guidelines / Australian and New Zealand Environment and Conservation Council, Agriculture and Resource, National water quality management strategy; no. 4.

http://www.environment.gov.au/water/publications/quality/nwqms-guidelines-4-vol1.html

Arboleda E. \& Peachey RBJ (2016) A study of water quality parameters of a selection of wells in Bonaire, 2016. CIEE Research Station Bonaire Report Number A001:2016

Becking \& Slijkerman (2012) Generic ecological assessment framework for coastal ecosystems in the Caribbean Netherlands. WUR Report number C122/12

Bell, P.R.F. 1992. Eutrophication and coral reefs-some examples in the Great Barrier. Reef Lagoon. Water Res. 26, 553-568

Bell et al 2007 Reevaluation of ENCORE: Support for the Eutrophication Threshold Model for Coral Reefs

Blauw A. \& Eleveld M (2020): Innovatieve monitoring BES-eilanden, ter ondersteuning van ecologische toestand kustwateren. Deltares rapport 11203730-020-ZWS-0001

Cooper et al., (2009) Temporal dynamics in coral bioindicators for water quality on coastal coral reefs of the Great Barrier Reef. Marine and Freshwater Research 59(8) 703-716 https://doi.org/10.1071/MF08016

De'ath G, Fabricius KE (2008) Water quality of the Great Barrier Reef: distributions, effects on reef biota and trigger values for the protection of ecosystem health. Final Report to the Great Barrier Reef Marine Park Authority. Australian Institute of Marine Science, Townsville. (104 pp.).

Fabricius KE, Cooper TF, Humphrey C, Uthicke S, De'ath G, Davidson J, LeGrand H, Thompson A, Schaffelke B. A bioindicator system for water quality on inshore coral reefs of the Great Barrier Reef. Mar Pollut Bull. 2012;65(4-9):320-32. doi: 10.1016/j.marpolbul.2011.09.004.

Fernandez A., A. Singh, R. Jaffé (2007) A literature review on trace metals and organic compounds of anthropogenic origin in the Wider Caribbean Region. Mar. Pollut. Bull., 54 (2007), pp. 1681-1691, 10.1016/j.marpolbul.2007.08.007

Geleuken et al., (2007). Eindrapport Milieunormen Nederlandse Antillen. Lucht \& Geluid Water \& Afvalwater Afval.

Hartmann, A. C. et al. Crude oil contamination interrupts settlement of coral larvae after direct exposure ends. Mar. Ecol. Prog. Ser. 536, 163-173 (2015).

Houk P., Comeros-Raynal M., Lawrence A., Sudek M., Vaeoso M., McGuire K., Regis J. (2020): Nutrient thresholds to protect water quality and coral reefs. Marine Pollution Bulletin 159 (2020) 111451. https://doi.org/10.1016/j.marpolbul.2020.111451

Lapointe and Mallin (2011). Nutrient Enrichment and Eutrophication on Fringing Coral Reefs of Bonaire and Curaçao, Netherlands Antilles. Report Harbor Branch Oceanographic Institute, Florida Atlantic University and Center for Marine Science, University of North Carolina Wilmington

Meesters, E.H., Bak, R.P.M., Westmacott, S., Ridgley, M., and Dollars, S. (1998). A fuzzy logic model to predict coral reef development under nutrient and sediment stress. Conserv. Biol. 12(5), 957-965.

Meesters, E. H., L. E. Becking, and M. van der Geest. (2019). Achteruitgang koraalriffen Caribisch Nederland: oorzaken en mogelijke oplossingen voor koraalherstel. Wageningen Marine Research, Den Helder.

MMP Inshore water and coral reef monitoring- Annual Report 2013/14 (Trigger values from GBRMPA 2010 \& DERM 2009)

NEPP (2020). Nature and Environment Policy Plan, 2020-2030

Parmar, D. Rawtani, Y.K. Agrawal (2016) Bioindicators: the natural indicator of environmental pollution. Front. Life Sci., 9 (2016), pp. 110-118, DOI:10.1080/21553769.2016.1162753

Physis student reports by CIEE (2006-2018)

Progressive Environmental Solutions, 2013. Interpretatie Grondwaterkwaliteitsmonitoring Bonaire, CN. Normering en monitoringsvoorstellen nutriëntenmonitoring kustzone. Rapportnummer 082013_2

Schaap and Slijkerman (2018) An environmental risk assessment of three organic UV-filters at Lac Bay, Bonaire, Southern Caribbean. Mar. Pollut. Bull., 135 (2018), pp. 490-495

Slijkerman DME, Dolfi Debrot, René Henkens, Matthijs van der Geest \& Sander Mücher (2018). Nexus interventions for small tropical islands - case study Bonaire. Ecosystem factsheet. Wageningen Marine Research https://edepot.wur.nl/471563 
Slijkerman, D.M.E., de Leon, R., and de Vries, P. (2014). A baseline water quality assessment of the coastal reefs of Bonaire, Southern Caribbean. Mar. Pollut. Bull. 86(1-2), 523-529. doi:

10.1016/j.marpolbul.2014.06.054.

Slijkerman DME, RBJ Peachey, PS Hausmann, HWG Meesters (2011) Eutrophication status of Lac, Bonaire, Dutch Caribbean. Including proposals for measures Report. Imares report number C093/11

Wijgerde Tim, Mike Van Ballegooijen, Reindert Nijland, Luna Van Der Loos, Christiaan Kwadijk, Ronald Osinga, Albertinka Murk, Diana Slijkerman (2020) Adding insult to injury: Effects of chronic oxybenzone exposure and elevated temperature on two reef-building corals. Sc. Tot. Env. 733 https://doi.org/10.1016/j.scitotenv.2020.139030

van der Geest, M., E. Meesters, and S. Mücher. 2020. Impact of terrestrial erosion on coral reef health at Bonaire: a plea for nature-inclusive "watershed-to-reef" based coastal management. Wageningen Marine Research, Den Helder.

US EPA (2012) Criteria for Bathing Recreational Waters. US EPA OFFICE OF WATER 820-F-12-058. https://www.epa.gov/sites/default/files/2015-10/documents/rwqc2012.pdf

Visser, P.M., Meesters, E.H., Duyl F.C. van (2019). Cruise report RV Pelagia 64PE430. Pp 79.

Waitt Institute (2017) The State of Curaçao's Coral Reefs. http://www.researchstationcarmabi.org/wpcontent/uploads/2017/08/Waitt-2017-Status-of-Curacaoan-reefs_Low-Res-1.pdf

UNEP (2003) Caribbean blue flag 


\section{Justification}

Report C074/21

Project Number: 4315100160

The scientific quality of this report has been peer reviewed by a colleague scientist and a member of the Management Team of Wageningen Marine Research

Approved: $\quad$ Gulsah Dogruer, MSc

Researcher

Signature:

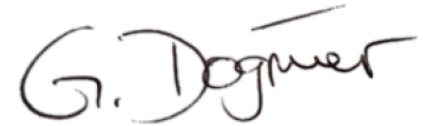

Date:

30 September 2021

Approved:

Drs. Jakob Asjes

Manager Integration

Signature:

Date:

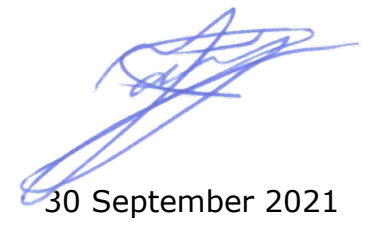




\section{Annex 1: Overview of relevant case studies}

Overview of relevant case studies, surveys and available datasets, with a short summary of findings, recommendations and results on published papers and reports. Only surface water studies included based on:

- Inventory among stakeholders. Reaction from Stinapa and OLB only, no reaction received from Sint Eustatius and Saba Stakeholders. Carmabi research is asked for, but execution is delayed and we have not received additional information yet.

- $\quad$ Search on www.CDBD.nl (nutrients, water quality, Saba, Sint Eustatius, Bonaire)

- Scopus (same key words). No additional studies found.

- Inquiry among scientists. No additional input received.

Studies related to coastal surface water reviewed below:

\begin{tabular}{|l|l|l|l|}
\hline Source & What & Years & Island \\
\hline LaPointe and Mallin (2011) & $\begin{array}{l}\text { Paper, reports and data, Raw data of } \\
\text { seasonal sampling for nutrients } \\
\text { (ammonium, nitrate, DIN, SRP, TDN, } \\
\text { TDP), (Chl a), stable nitrogen isotopes } \\
(! 15 N) \text { in reef macro-algae, and biotic } \\
\text { Cover of shallow and deep reef sites }\end{array}$ & $\begin{array}{l}2006- \\
2008\end{array}$ & Bonaire \\
\hline Slijkerman et al 2014 & $\begin{array}{l}\text { Paper, data, reports on seasonal sampling } \\
\text { Raw data of seasonal sampling for } \\
\text { nutrients (ammonium, nitrate, DIN, SRP, } \\
\text { TDN, TDP), (Chl a), stable nitrogen } \\
\text { isotopes (!15N) in reef macroalgae, of } \\
\text { shallow and deep reef sites }\end{array}$ & 2013 & Bonaire \\
\hline $\begin{array}{l}\text { Physis 1-21 student } \\
\text { reports }\end{array}$ & $\begin{array}{l}\text { Various } \\
\text { Pelagia report }\end{array}$ & $\begin{array}{l}\text { Deep reef research on nutrients and algae } \\
\text { substrates }\end{array}$ & \\
\hline Slijkerman et al., 2010 & Butrients, bacteria, epiphytes, hard & Bonaire- Lac \\
\hline
\end{tabular}

Studies related to groundwater, reviewed in paragraph 6.2.2:

\begin{tabular}{|l|l|l|l|}
\hline Source & What & Years & Island \\
\hline $\begin{array}{l}\text { Progressive Environmental } \\
\text { Solutions, } 2013\end{array}$ & $\begin{array}{l}\text { Interpretation groundwater quality } \\
\text { monitoring at Bonaire, with monitoring } \\
\text { proposal for the coastal zone. }\end{array}$ & 2013 & Bonaire \\
\hline $\begin{array}{l}\text { Arboleda E. \& Peachey RBJ } \\
(2016)\end{array}$ & $\begin{array}{l}\text { A study of water quality parameters of a } \\
\text { selection of wells in Bonaire, }\end{array}$ & 206 & Bonaire \\
\hline
\end{tabular}




\section{Study: Nutrient Enrichment and Eutrophication on Fringing Coral Reefs of Bonaire and}

Curaçao, Netherlands Antilles

Researchers: Lapointe and Mallin (2011)

Island: Bonaire

Monitoring performed: $2006-2008$

Summary of work: Research performed by LaPointe and Mallin resulted in a reports, paper, data, on seasonal sampling for nutrients (ammonium, nitrate, DIN, SRP, TDN, TDP), Chl a, stable nitrogen isotopes in reef macro-algae of shallow and deep reef sites (10 in total).

They refer to previous studies at undisturbed Caribbean coral reefs, which typically have very low or undetectable ammonium concentrations (< $0.2 \mu \mathrm{M}$, Bell 1992; Lapointe and Smith 1987; Lapointe et al. 1993). Lapointe and Mallin reported however eutrophic conditions in the coastal waters of Bonaire at various sites and moments. Sampling protocol is described in detail, replicate samples $(n=4)$.

Analysis was conducted at various universities in the USA. Although Lapointe and Mallin have sampled across years and seasons, they do not describe the variability among seasons and years but only report mean values. They note a high variability within and among sites but do not reflect on seasons and years as an explanation. The available raw data could be used to detect any of these potential patterns.

Levels of nutrients observed: The overall shallow reef mean ammonium concentration observed by Lapointe and Mallin was $0.89 \mu \mathrm{M}$, the overall median ammonium at was $0.61 \mu \mathrm{M}$. However, on several samplings unusually high ammonium concentrations (up to $\sim 10 \mu \mathrm{M}$ ) occurred at both shallow and deep reefs adjacent to the Cargill salt ponds, but also at a location upstream of this point. Spatial differences for nitrate were also observed. Highest nitrate concentrations consistently occurred on reefs in urbanized areas at both deep and shallow reefs, being higher at deeper reefs. The overall median DIN concentration at shallow reefs was $1.11 \mu \mathrm{M}$ and thus above the threshold for eutrophication. Also at deep reefs the threshold value was exceeded. Ammonium dominated the DIN pool. Mean Chl a concentrations were $0.19 \mu \mathrm{g} / \mathrm{l}$, slightly under the threshold value. Highest $\mathrm{Chl}$ a concentrations occurred on reefs adjacent to urbanized, nutrient enriched areas. In contrast, low Chl a values of $\sim 0.05-0.1 \mu \mathrm{g} / \mathrm{l}$ occurred at upstream reef sites and the offshore reference site, underscoring the importance of land-based nutrient enrichment to eutrophication on fringing reefs. Soluble phosphorus concentrations averaged $\sim 0.1 \mathrm{M}$, a level that also represents the phosphorus threshold for eutrophication. TDN/TDP ratios averaged 52 indicating strong P-limitation of algal growth. The stabile isotope $15 \mathrm{~N}$ values of macro-algae on shallow and deep reefs on Bonaire were $+1.53 \%$. Variability: Within and among stations high variability was observed for various nutrients (nitrogen and ammonium, not DIN), especially at the shallow reefs, not at deeper reefs.

\section{Lessons learned:}

- Study performed BEFORE treatment plant was installed. Levels of both nitrogen, phosphorus and chlorophyll-a were above or near threshold levels, but varied spatially (highest near industry or urban areas), stable isotope values did not exceed threshold level.

- Shallow and deep reefs can differ in concentrations reported, indicating the importance of sampling both depths

- Seasonal variation probably steered the reported variability within stations. It is important to include seasonal sampling to understand the patterns.

- $\quad$ Raw data available, additional statistical analysis can be done. 
Researchers: Slijkerman, DeLeon, De Vries

Island: Bonaire

Monitoring performed: $2011-2013$

Summary of work: Research performed by Slijkerman et al resulted in reports, a paper, and raw data, on seasonal sampling for nutrients (ammonium, nitrate, DIN, ureum, TP, PO4), Chl a, e.coli, stable nitrogen isotopes in reef macro-algae of shallow (all years) and deep reef sites (only in 2011). Slijkerman et al report sampled in the coastal waters of Bonaire at various sites (12) and moments (4). Sampling protocol is described in detail, replicate samples $(n=3)$. Analysis was conducted on site (phyisco chemical, E.coli), nutrients and stable isotopes were analyses at NIOZ Yerseke. The following research questions were discussed:

- $\quad$ Are environmental safe threshold levels of water quality exceeded? (yes)

- Is temporal (over the years), or seasonal variation (November-May) of water quality observed? (yes)

- $\quad$ Does water quality vary among locations or regions in Bonaire? (yes)

- $\quad$ Based on experience and results, what are recommendations for future monitoring of water quality?

\section{Levels of nutrients observed and related threshold levels}

DIN ranged from $0.01 \mu \mathrm{M}$ till $2.69 \mu \mathrm{M}$. DIN environmental threshold level of $1 \mu \mathrm{M}$ is exceeded at $18 \%$ of the samples, taken at some southern and urban locations. Exceeding the threshold was not attributed to a specific season. DIN consists of NOX and $\mathrm{NH}_{4}$. The contribution of either ammonium or nitrate to DIN varied per location and season. The offshore reference water clearly differed from coastal zone water. Offshore water consisted $80 \%$ of $\mathrm{NH}_{4}$ contributing to DIN, whereas the shore had higher nitrate than $\mathrm{NH} 4$. Phosphorus (PO4) ranged from 0-0.16 $\mu \mathrm{M}$. Based on average values the threshold was not exceeded. Chlorophyll-a concentrations ranged from 0.02-0.42 $\mu \mathrm{g} / \mathrm{l}$, exceeding the threshold level occasionally within a single sample but on average, no exceedance of the threshold was observed.

Variability: Spatial and temporal variability was observed. Southern and urban location had higher nutrient and chl-a levels (in general). November samples showed slightly higher nitrogen levels than May samples but lower phosphorus levels. A decrease of DIN was observed over the 2 years, but in increase of phosphorus (PO4) and chlorophyll-a. Difference between shallow and deep reef was not observed in 2011 (in contrast to Lapointe and Mallin), and the study continued in 2012 and 2013 a shallow reefs only. We can thus not indicate whether the lack of difference in water quality between depths was a 1 time observation, or a structural one.

\section{Lessons learned and recommendations done:}

- Water quality varied in time (both season and year) and space, and occasionally exceeded threshold levels for eutrophication. No structural eutrophic conditions are reported by the indicators used. However, the lack of information on primary producers (cyanobacteria, macro algae, coral) hampers a complete analysis on the status. Primary producers consume more nutrients (continues flux) and might lower ambient nutrient concentration. This might be illustrated by the increased chlorophyll-a levels.

Water quality of 2006-2008 reported by Lapointe and Mallin was worse than the water quality reported for 2011-2013.

- $\quad$ It is recommended to

- continue the monitoring of water quality over several years at the same frequency and locations. Include interval sampling during heavy rains. Consider additional locations. Add depths in order to elucidate a structural or incidental observation.

- Coastal water quality should be analyzed in context with groundwater quality, pressures (run-off, fisheries, climate change) treatment plant performance, benthic coverage and benthic quality. It is advised to synchronize the monitoring programs, and to analyze the datasets in a coherent way. 
Researchers: Visser, Van Duyl ea

Island: Bonaire

Monitoring performed: 2018

Summary of work: Research performed by Visser et al., 2018. 8 locations along the coast of Bonaire. Nutrient concentrations, (PO4, NH4, NO3, NO2, DIC/alkalinity) particulate and dissolved organic matter, phytoplankton and bacterial and viral abundance were sampled close to the bottom between 50 and $80 \mathrm{~m}$ in front of Kralendijk at various depths until approximately $300 \mathrm{~m}$ deep. Three to ten different depths were sampled for inorganic nutrients. Work was performed in January. Nutrient data were not reported explicitly.

\section{Levels of nutrients}

In the surface layer low inorganic nutrient concentrations were found (DIN $<1 \mu \mathrm{M}, \mathrm{PO} 4<0.06 \mu \mathrm{M})$ and in the deeper layer enhanced concentration of nitrate and soluble reactive phosphorous. Steep inorganic nutrient gradients were found just above the depth zone in which cyanobacterial mats occur along Kralendijk. Steep gradients in nutrients, temperature and salinity were also found around 50-80 $\mathrm{m}$ depth with significantly higher concentrations of PO4, NO2 and NO3 below the nutricline than above it in mixed surface water. 2 distinct water masses were observed (along the depth). One with enhanced nutrient concentrations (up to $35 \mathrm{~m}$ depth). Deep cyanobacterial mats between 55 and 70 $\mathrm{m}$ might benefit of the settlement of particulate organic matter (enhanced algal concentration), as well as higher (in)organic nutrient concentrations of NOx and PO4. Only NH4 concentrations were higher in surface waters than below the halocline at all stations along the leeward coast of Bonaire.

Variability: not measured

\section{Lessons learned and recommendations done:}

- $\quad$ Not reported

- Study relevant for deep reefs, not for shallow 
Research: Eutrophication status of Lac, Bonaire, Dutch Caribbean. Including proposals for measures

Researchers: DME Slijkerman, RBJ Peachey, PS Hausmann, HWG Meesters

Island: Bonaire

Monitoring performed: 2010

Summary of work: The purpose of this baseline study was to assess the trophic status of Lac by analysing indicators of eutrophication: Nutrients, enterococci, epiphyte loads of seagrasses, Benthic community composition of the back reef. The monitoring was performed at 32 sites within the bay and 1 control site outside the bay in December 2010. A $15 \mathrm{ml}$ sample was dispensed and frozen and subsequently air-freighted to the Woods Hole Oceanographic Institute Department of Marine Chemistry and Geochemistry for analysis of nutrients. The facility operated a Lachat Instruments QuickChem 8000 four-channel continuous flow injection system, specified and approved by the United States Environmental Protection Agency (1985). Three of the four observed indicators point towards an ecosystem that is under stress from eutrophication. The levels of nutrients in the bay exceeded thresholds for open coral reef systems.

Lessons learned and recommendations done:

- Lac, due to multiple pressures, can be a source of nutrients to the outer reef system

- Enterococci can come from wildlife and cattle

- Include monitoring of pressures due distinguish natural sources of nutrients and bacteria from anthropogenic sources. 
Research: Various student reports in Physis (CIEE) papers 2006-2018

Researchers: Various

Island: Bonaire

Monitoring performed: incidental over period 2006-2018

Summary of work: Research performed by graduate students at CIEE research station. Reported in CIEE student journal "Physis". Includes numerous studies that report on nutrients, sedimentation, bacterial levels, benthic cover etc. 21 "journals" have been reported, each with numerous studies described. In the underlying assignment, these studies cannot all be reviewed and summarized. Stand-alone projects, information on levels can however be used as indication. Method section is briefly described, and conclusions drawn should be carefully evaluated (student observations only). In this summary, no evaluation on reported levels is done.

In earlier years, LaMotte Nitrate-Nitrogen kit and CHEMets Phosphate kit were used to analyse nutrients, and levels were reported in ppm.

\section{Lessons learned and recommendations done:}

- $\quad$ Nutrients kits were used as an indication of nutrient levels.

Range/sensitivity for nitrate is $0,0.2,0.4,0.6,0.8,1.0$ ppm NO3- $\mathrm{N}^{1}$ and absorbance values were taken with the fluorometer. The nitrogen concentration was determined using a standard calibration curve with a minimum nitrogen detection level at $0.03 \mu \mathrm{M}$.

Range/sensitivity for phosphorus was 0-1 \& 1-10 ppm. MDL: $0.05 \mathrm{ppm}^{2}$

- $\quad$ Review and evaluation of reported water quality to be carried out in other assignment.

\footnotetext{
${ }^{1}$ https://lamotte.com/products/environmental-science-education/partnership-programs/the-globe-program/nitrate-nitrogen-test-kit-3615-01

${ }^{2}$ https://www.chemetrics.com/product/phosphate-ortho-chemets-visual-ki-k-8510/
} 


\section{Annex 2: Relevant policy frameworks and treaties}

\section{Local (Valid for individual BES island):}

- Ban on oxybenzone and octinoxate containing sunscreen on Bonaire as of 1 January 2022.

- Bonaire Wastewater Waste water Ordinance of 5 July 2012 (not yet fully in force)

- Island ordinance on irrigation, in draft form and not in force.

\section{National level}

\section{Law VROM BES}

BES Housing, Spatial Planning and the Environment Act (elaboration partly laid down in the NEPP and Bgim (BES Large Establishments Environmental Management Decree). Concerns activities which require a permit, such as oil transhipment). Regular activities are covered by the permit. It also describes how to act in the event of calamities (as well as monitoring). For enforcement purposes this monitoring of water quality could be a "finger on the pulse" function.

\section{BES Maritime Act}

The BES Maritime Act lays down rules for activities in or near the sea, which may have an impact on, among other things, the environment and nature of the coast and seas, and their pollution. The loading and unloading of hazardous substances (both at sea and between sea and land via, for example, a pier or jetty) is, for example, subject to permit requirements, and calamities must be reported.

8.3 Regional and international:

The Netherlands recognises the objectives set out in the international framework of the Convention on Biological Diversity (CBD) and forms part of the convention. The objectives of the CDB include conservation and sustainable use of biodiversity. There are two protocols in force under the CBD that the Netherlands has ratified, namely the Cartagena Protocol (Convention) and the Nagoya Protocol.

\section{Cartagena Convention}

The Cartagena Convention has three aspects. In addition to the SPAW Protocol and oil-spill Protocol, the LBS Protocol specifically addresses land-based pollution ("Protocol concerning Pollution from Landbased Sources and Activities to the Convention for the Protection and Development of the Marine Environment of the Wider Caribbean Region"). The LBS and the oil spills protocol are jointly covered by the UN/Cartagena Convention's AMEP (Assessment \& Management of Environmental Pollution) programme.

The LBS main text provides general obligations and a legal framework for regional cooperation. The operational annexes describe the work to be carried out by each contracting party. They also provide guidelines for the development of regional actions.

o Annex I contains a list of land-based sources and activities and related pollutants of greatest concern to the marine environment;

o Annex II outlines and establishes the process for the development of regional standards and practices for the prevention, reduction and control of the sources and activities listed in Annex I. o Annex III establishes specific regional wastewater restrictions for domestic wastewater; and o Annex IV requires each Contracting Party to develop plans, programs and other measures to prevent, reduce and control non-point source pollution from agriculture.

Although the Netherlands have ratified the LBS protocol, it remains unclear (date 12/11/2020) whether the ratification also includes the Caribbean Netherlands).

\section{Convention on Biological Diversity}

Convention on Biological Diversity - Nagoya protocol includes its targets in so-called AICHI targets. The following aichi targets are relevant in relation to coastal water quality: 
o Target 8: By 2020, pollution, including from excess nutrients, has been brought to levels that are not detrimental to ecosystem function and biodiversity.

o Target 10: By 2015, the multiple anthropogenic pressures on coral reefs, and other vulnerable ecosystems impacted by climate change or ocean acidification are minimized, so as to maintain their integrity and functioning.

\section{UN / Sustainable Development Goals (SDGs)}

UN / Sustainable Development Goals (SDGs) and their sub-targets relevant in relation to coastal water quality

o SDG 6 (Clean Water and Sanitation):

By 2030 , improve water quality by reducing pollution, eliminating dumping and minimising release of hazardous chemicals and materials, halving the proportion of untreated wastewater and substantially increasing recycling and safe reuse globally".

By 2020, protect and restore water-related ecosystems

Support and strengthen the participation of local communities in improving water and sanitation management

o Goal 14: Life Below Water

By 2025, prevent and significantly reduce marine pollution of all kinds, in particular from land-based activities, including marine debris and nutrient pollution

Minimize and address the impacts of ocean acidification, including through enhanced scientific cooperation at all levels 


\title{
Annex 3: List of regional marine laboratories
}

\author{
Country/state \\ Bahamas \\ Barbados \\ Belize \\ Belize \\ Bermuda \\ Cayman Islands \\ Costa Rica \\ Cuba \\ Curaçao \\ Curaçao \\ Grenada \\ Guadeloupe \\ Jamaica \\ Jamaica \\ México \\ Panama \\ Turks and Caicos Islands \\ USA - Florida \\ USA - Florida \\ USA - Florida \\ US Virgin Islands \\ US Virgin Islands

\section{Institute} \\ Perry Institute for Marine Science \\ Centre for Resource Management and Environmental Studies \\ University of the West Indies \\ Glover's Reef Research Station \\ Wildlife Conservation Society (WCS) \\ Smithsonian Institution - Carrie Bow Cay Field Station \\ University of Belize \\ Bermuda Institute of Ocean Sciences (BIOS) \\ Central Caribbean Marine Institute \\ Centro de Investigaciones en Ciencias del Mar y Limnologia (CIMAR) \\ Universidad de Costa Rica (UCR) \\ Centro de Investigaciones Marinas \\ Universidad de la Habana \\ Carmabi Foundation \\ Curaçao Sea Aquarium (CSA) \\ Marine Biology Program \\ Université des Antilles \\ Discovery Bay Marine Laboratory \\ Port Royal Marine Laboratory \\ Institute of Marine Sciences and Limnology \\ Universidad Nacional Autónoma de México \\ Center for Tropical Island Biodiversity Studies \\ The School for Field Studies \\ Center for Marine Resource Studies \\ The School for Field Studies (SFS) \\ Nova Southeastern University Oceanographic Center \\ Nova Southeastern University (NSU) \\ Coral Restoration Foundation International, Inc. \\ Archie Carr Center for Sea Turtle Research \\ Texas A\&M Univsersity at Galveston \\ MacLean Marine Science Center \\ University of the Virgin Islands (UVI) \\ Center for Marine and Environmental Studies \\ Virgin Islands Environmental Resource Station \\ University of the Virgin Islands (UVI)
}


Wageningen Marine Research

$\mathrm{T}+31(0) 317480900$

E: marine-research@wur.nl

www.wur.eu/marine-research

Visitors' address

- Ankerpark 271781 AG Den Helder

- Korringaweg 7, 4401 NT Yerseke

- Haringkade 1, 1976 CP IJmuiden
With knowledge, independent scientific research and advice, Wageningen Marine Research substantially contributes to more sustainable and more careful management, use and protection of natural riches in marine, coastal and freshwater areas.

Wageningen Marine Research is part of Wageningen University \& Research. Wageningen University \& Research is the collaboration between Wageningen University and the Wageningen Research Foundation and its mission is: 'To explore the potential for improving the quality of life' 